\title{
High-throughput metabarcoding reveals the effect of physicochemical soil properties on soil and litter biodiversity and community turnover across Amazonia
}

\author{
Camila D Ritter Corresp., 1,2 , Alexander Zizka ${ }^{1,2}$ \\ Henrik Nilsson ${ }^{1,2}$, Alexandre Antonelli 1,2,6,7 \\ ${ }^{1}$ Gothenburg Global Biodiversity Centre, Göteborg, Sweden \\ 2 Department of Biological and Environmental Sciences, University of Gothenburg, Gothenburg, Sweden \\ 3 Centre for Environmental and Climate Research, Lund University, Lund, Sweden \\ 4 Department of Biology, University of Turku, Turku, Finland \\ 5 Natural History Museum of Denmark, University of Copenhagen, Denmark, Copenhagen, Denmark \\ 6 Gothenburg Botanical Garden, Göteborg, Sweden, Gothenburg, Sweden \\ 7 Department of Organismic and Evolutionary Biology, Harvard University, Cambridge, United States \\ Corresponding Author: Camila D Ritter \\ Email address: camila.ritter@gu.se
}

Fabian Roger ${ }^{3}$, Hanna Tuomisto ${ }^{4}$, Christopher Barnes ${ }^{5}$, R.

Background. Knowledge on the globally outstanding Amazonian biodiversity and its environmental determinants stems almost exclusively from aboveground organisms, notably plants. In contrast, the environmental factors and habitat preferences that drive diversity patterns for micro-organisms in the ground remain elusive, despite the fact that micro-organisms constitute the overwhelming majority of life forms in any given location, in terms of both diversity and abundance. Here we address how the diversity and community turnover of operational taxonomic units (OTU) of organisms in soil and litter respond to soil physicochemical properties; whether OTU diversities and community composition in soil and litter are correlated with each other; and whether they respond in a similar way to soil properties. Methods. We used recently inferred OTUs from highthroughput metabarcoding of the 16S (prokaryotes) and 18S (eukaryotes) genes to estimate OTU diversity (OTU richness and effective number of OTUs) and community composition for prokaryotes and eukaryotes in soil and litter across four localities in Brazilian Amazonia. All analyses were run separately for prokaryote and eukaryote OTUs, and for each group using both presence-absence and abundance data. Combining these with novel data on soil chemical and physical properties, we identify abiotic correlates of soil and litter organism diversity and community structure using regression, ordination, and variance partitioning analysis. Results. Soil organic carbon content was the strongest factor explaining OTU diversity (negative correlation) and $\mathrm{pH}$ was the strongest factor explaining community turnover for prokaryotes and eukaryotes in both soil and litter. We found significant effects also for other soil variables, including both chemical and physical 
properties. The correlation between OTU diversity in litter and in soil was non-significant for eukaryotes and weak for prokaryotes. The community compositions of both prokaryotes and eukaryotes were more separated among habitat types (terra-firme, várzea, igapó and campina) than between substrates (soil and litter). Discussion. In spite of the limited sampling (four localities, 39 plots), our results provide a broad-scale view of the physical and chemical correlations of soil and litter biodiversity in a longitudinal transect across the world's largest rainforest. Our methods help to understand links between soil properties, OTU diversity patterns, and community composition and turnover. The lack of strong correlation between OTU diversity in litter and in soil suggests independence of diversity drives of these substrates and highlights the importance of including both measures in biodiversity assessments. Massive sequencing of soil and litter samples holds the potential to complement traditional biological inventories in advancing our understanding of the factors affecting tropical diversity. 


\section{Author Cover Page}

2

3 THIS IS A REVISION OF MANUSCRIPT: 26029

4

5 Article submission to PeerJ

6 Manuscript category: Research Articles

7 Collection: "Endless forms: Advances in evolutionary analyses of biodiversity"

9 Title:

High-throughput metabarcoding reveals the effect of physicochemical soil properties on soil and litter biodiversity and community turnover across Amazonia.

12 Camila D. Ritter ${ }^{1,2^{*}}$, Alexander Zizka ${ }^{1,2}$, Fabian Roger ${ }^{3}$, Hanna Tuomisto ${ }^{4}$, Christopher Barnes ${ }^{5}$,

13 R. Henrik Nilsson ${ }^{1,2 \S}$, Alexandre Antonelli ${ }^{1,2,6,7 \S}$

$14{ }^{1}$ Gothenburg Global Biodiversity Centre, Göteborg, Sweden.

$15{ }^{2}$ Department of Biological and Environmental Sciences, University of Gothenburg, Sweden.

$16{ }^{3}$ Centre for Environmental and Climate Research, Lund University, Sweden.

$17{ }^{4}$ Department of Biology, University of Turku, Finland.

$18{ }^{5}$ Natural History Museum of Denmark, University of Copenhagen, Denmark.

$19{ }^{6}$ Gothenburg Botanical Garden, Göteborg, Sweden.

$20{ }^{7}$ Department of Organismic and Evolutionary Biology, Harvard University. 
21 *Corresponding author: Camila Ritter, kmicaduarre@gmail.com. Phone: +46 723924447, Carl

22 Skottsbergs gata 22B, Box 461, SE 40530 Göteborg, Sweden

23 Both are senior authors in this paper. 


\section{Abstract}

Background. Knowledge on the globally outstanding Amazonian biodiversity and its environmental determinants stems almost exclusively from aboveground organisms, notably plants. In contrast, the environmental factors and habitat preferences that drive diversity patterns for micro-organisms in the ground remain elusive, despite the fact that micro-organisms constitute the overwhelming majority of life forms in any given location, in terms of both diversity and abundance. Here we address how the diversity and community turnover of operational taxonomic units (OTU) of organisms in soil and litter respond to soil physicochemical properties; whether OTU diversities and community composition in soil and litter are correlated with each other; and whether they respond in a similar way to soil properties.

Methods. We used recently inferred OTUs from high-throughput metabarcoding of the 16S (prokaryotes) and 18S (eukaryotes) genes to estimate OTU diversity (OTU richness and effective number of OTUs) and community composition for prokaryotes and eukaryotes in soil and litter across four localities in Brazilian Amazonia. All analyses were run separately for prokaryote and eukaryote OTUs, and for each group using both presence-absence and abundance data. Combining these with novel data on soil chemical and physical properties, we identify abiotic correlates of soil and litter organism diversity and community structure using regression, ordination, and variance partitioning analysis.

Results. Soil organic carbon content was the strongest factor explaining OTU diversity (negative correlation) and $\mathrm{pH}$ was the strongest factor explaining community turnover for prokaryotes and eukaryotes in both soil and litter. We found significant effects also for other soil variables, including both chemical and physical properties. The correlation between OTU diversity in litter 
47 and in soil was non-significant for eukaryotes and weak for prokaryotes. The community

48 compositions of both prokaryotes and eukaryotes were more separated among habitat types

49 (terra-firme, várzea, igapó and campina) than between substrates (soil and litter).

50 Discussion. In spite of the limited sampling (four localities, 39 plots), our results provide a

51 broad-scale view of the physical and chemical correlations of soil and litter biodiversity in a

52 longitudinal transect across the world's largest rainforest. Our methods help to understand links

53 between soil properties, OTU diversity patterns, and community composition and turnover. The

54 lack of strong correlation between OTU diversity in litter and in soil suggests independence of

55 diversity drives of these substrates and highlights the importance of including both measures in

56 biodiversity assessments. Massive sequencing of soil and litter samples holds the potential to

57 complement traditional biological inventories in advancing our understanding of the factors

58 affecting tropical diversity. 


\section{Introduction}

Tropical rainforests are mega-diverse and environmentally heterogeneous biomes, and their biodiversity has been shown to vary considerably over space. In Amazonia, the world's largest rainforest that covers most of northern South America, geology and soil physicochemical properties are often considered crucial in regulating the biotic dynamics, vegetation, and diversity patterns at local to regional scales (Vogel et al., 2009; Laurence et al., 2010; Higgins et al., 2011; Friesen et al., 2011; Tuomisto et al., 2016).

For instance, diversity and community composition of plants are influenced by geology and physicochemical soil properties (e.g. Vogel et al., 2009; Laurence et al., 2010; Higgins et al., 2011; Friesen et al., 2011; Tuomisto et al., 2014, 2016, Tedersoo et al., 2016). In particular, the availability of soil nutrients and soil cation concentration are important factors determining plant species composition and turnover (Tuomisto et al., 2003; Laurence et al., 2010; Higgins et al., 2011; Baldeck et al., 2016; Tuomisto et al., 2016; Cámara-Leret et al., 2017). Additionally, soil properties, in particular phosphorus, can affect the taxonomic composition of microbial communities (Buckley and Schmidt, 2001; Faoro et al., 2010; Navarrete et al., 2013). In addition, $\mathrm{pH}$ is known to shape microbial diversity (e.g., Osborne et al., 2011; Kuramae et al., 2012; Bates et al., 2013; Barnes et al., 2016).

9 Different soil layers may show different patterns of biodiversity (Hinsinger et al., 2009). For instance, the taxonomic composition of nematode species clustered in six trophic guilds (bacterial feeders, fungal feeders, root associates, plant parasites, omnivores, and predators) has 
82 been found to vary between the mineral soil layer and the organic matter layer (litter) above it

83 (Porazinska et al., 2012). In Amazonia, litter layers vary with habitat type and the length of the

84 inundation period. Unflooded forests (terra-firme) are particularly rich in litter. In addition,

85 flooded forests are also rich in litter and the litter layer increases with increasing length of the

86 inundation period (Myster, 2017). Besides inundation, several other factors influence litter

87 accumulation and thereby decomposition rates and nutrient cycling. These include leaf

88 abscission and species composition (e.g. Gregorich et al., 2016), which have implications for the

89 diversity and community structure of soil and litter-inhabiting organisms. However, the strength

90 of soil-litter interactions varies, and a study conducted in Canada reported no influence of soil

91 physicochemical properties on litter decomposition (Gregorich et al., 2016). This may indicate a

92 difference in biodiversity patterns (due to different drivers and biomass) between soil and litter 93 layers.

95 The diversity and composition of Amazonian soil and litter communities remain poorly understood, despite recent studies on soil micro-organismic communities (e. g. Basset et al., 97 2012; Mahé et al., 2017; Ritter et al., 2018). This lack of knowledge, especially in taxonomic groups such as fungi, protists, nematodes, and bacteria, is problematic given the important roles of these groups in a wide range of biotic processes (Falkowski et al., 2008; Stajich et al., 2009; Friesen et al., 2011). To tackle his lack of knowledge, high-throughput amplicon-based sequencing analyses such as DNA metabarcoding (Taberlet et al., 2012) now allow examination

102 of soil diversity patterns (Bardgett and van der Putten, 2014). However, most studies so far have 103 been focused on one or a few taxonomic groups, which renders general conclusions on the 104 effects of soil properties on biodiversity difficult (e.g. Faoro et al., 2010; Laurence et al., 2010; 
105 Navarrete et al., 2013; Barnes et al., 2016). Understanding microbial diversity and communities

106 and their relation to soil physicochemical properties on a broad taxonomic scale is therefore

107 crucial in any location, but particularly so in mega-diverse regions such as Amazonia to access

108 general conclusion about the abiotic drivers of diversity.

110 In this study, we test the effect of physicochemical soil properties on soil and litter biodiversity

111 and community turnover at four localities along a west-to-east transect across Brazilian 112 Amazonia. We base diversity estimates on operational taxonomic units (OTUs) from 113 environmental DNA of the ribosomal 16S (prokaryote) and nuclear ribosomal 18S (eukaryote) 114 genes. Specifically, we seek to answer the following questions: Are OTU diversity and turnover 115 related to physical and chemical soil properties? If so, what are the most important soil 116 properties? Are OTU diversity and community composition correlated when quantified for the 117 litter layer vs. the underlying soil? All questions are addressed separately for eukaryotes (18S) 118 and prokaryotes (16S) using both presence-absence and abundance data.

\section{Materials and Methods}

\subsection{SAMPLING DESIGN AND LOCALITIES}

122 We sampled four localities along the Amazon River (Fig. 1) following the sampling design of 123 Tedersoo et al. (2014). Detailed locality descriptions are available in Ritter et al. (2018). Briefly, 124 we sampled all depths of the litter layer above the mineral soil (all organic matter, including 125 leaves, roots, and animal debris) and the top $5 \mathrm{~cm}$ of the mineral soil in a total of 39 circular 
126 plots, each with a radius of $28 \mathrm{~m}$. We chose 20 random trees inside each plot and collected litter

127 and soil on both sides of each tree. We then pooled the samples by substrate to obtain one soil

128 and one litter sample per plot. Each sample was stored in a plastic bag with the same weight than

129 soil/litter samples of sterilized white silica gel of $1-4 \mathrm{~mm}$ grain size, pre-treated for two

130 minutes of microwave heating $(800 \mathrm{~W})$ and $15 \mathrm{~min}$ of UV light. The bags were stored at room

131 temperature (around $30{ }^{\circ} \mathrm{C}$ ) in a dark box to avoid exposure to light. Once they arrived in

132 Sweden, a period between 7 - 30 days, the samples were frozen $\left(-20{ }^{\circ} \mathrm{C}\right)$. We sampled in

133 different habitat types, which can be summarized as terra-firme, várzeas, igapós, and campinas.

134 These are four of the commonly recognised main Amazonian environments. Terra-firme is

135 characterised by not being inundated during the annual flood season, and terra-firme forests

136 generally have tall stature and complex canopy structure (IBGE, 2004). In contrast, várzeas and

137 igapós are seasonally flooded and remain submerged during parts of the year. Várzeas are

138 flooded by white-water rivers, which carry a large load of suspended sediments, whereas igapós

139 are flooded by black-water rivers, which bring a small load of suspended sediments but a high

140 concentration of organic acids (Junk et al., 2011). Finally, campinas have nutrient-impoverished

141 sandy soils and forests with a reduced stature and relatively simple canopy structure (Prance,

142 1996; IBGE, 2004).

144 Our sampling was carried out in four areas: Benjamin Constant ( 9 plots covering terra-firme, várzea and igapó), our westernmost locality, approximately 1,100 km west of Manaus in the

146 upper Amazonas River (4.383 S, 70.017 W; Fig 1A); Jaú national park (6 plots covering terra-

147 firme and igapó; $1.850^{\circ} \mathrm{S}, 61.616^{\circ} \mathrm{W}$; Fig 1B) and Novo Airão (3 plots covering campinas;

$1482.620^{\circ} \mathrm{S}, 60.944^{\circ} \mathrm{W}$; Fig 1C), on the west side of the Negro River; Reserva do Cuieras (6 plots 
149 covering terra-firme and igapó; $2.609^{\circ} \mathrm{S}, 60.217^{\circ} \mathrm{W}$; Fig 1D) and Reserva da Campina (3 plots

150 covering campinas; $2.592^{\circ} \mathrm{S}, 60.030^{\circ} \mathrm{W}$; Fig 1E), on the east side of the Negro River; and

151 Caxiaunã (12 plots covering campinas, terra-firme, várzea, and igapó), a national forest located

$152350 \mathrm{~km}$ west of Belém $\left(1.7352^{\circ} \mathrm{S}, 51,463^{\circ} \mathrm{W}\right.$; Fig $\left.1 \mathrm{~F}\right)$, which constitutes our easternmost

153 locality. The sample collection was authorized by Brazilian authorities: ICMBio (registration 154 number 48185-2) and IBAMA (registration number 127341).

We determined the physicochemical soil properties of each plot from three soil samples per plot, totalling 117 samples. The $\mathrm{pH}$ was measured in water (soil: water ratio 1:2.5). The exchangeable concentrations were measured for sodium $(\mathrm{Na})$, potassium $(\mathrm{K})$, and phosphorus $(\mathrm{P})$ using Mehlich-1 extraction (unit $\mathrm{mg} / \mathrm{dm}^{3}$ ) and for calcium and magnesium (Ca, $\mathrm{Mg}$ ) using $\mathrm{KCl}$ (1 $\mathrm{mol} / \mathrm{L}$ ) extraction (unit $\mathrm{cmol}_{\mathrm{c}} / \mathrm{dm}^{3}$ ). The sum of all exchangeable bases (SB; which comprises $\mathrm{K}^{+}, \mathrm{Ca}^{2+}, \mathrm{Mg}^{2+}$, and $\mathrm{Na}^{+}$; unit $\mathrm{cmol}_{\mathrm{c}} / \mathrm{dm}^{3}$ ) was then calculated. We also estimated exchangeable aluminium $\left(\mathrm{Al}\right.$ and $\mathrm{H}+\mathrm{Al}$ unit $\left.\mathrm{cmol}_{\mathrm{c}} / \mathrm{dm}^{3}\right)$ extracted with calcium acetate $(0.5 \mathrm{~mol} / \mathrm{L}$ at $\mathrm{pH} 7.0)$, aluminium saturation index (m; unit \%), and Base Saturation Index (V; unit \%). The effective cation exchange capacity $(\mathrm{t})$ as well as the cation exchange capacity $(\mathrm{T})$ were measured at $\mathrm{pH} 7.0$ (unit $\mathrm{cmol}_{\mathrm{c}} / \mathrm{dm}^{3}$ ). The organic matter (O.M) was quantified (unit $\mathrm{g} / \mathrm{kg}$ ) and the organic carbon (C) was estimated from the organic matter as: $\mathrm{C}=\mathrm{O} . \mathrm{M} / 1.724$ - Walkley-Black (unit $\mathrm{g} / \mathrm{kg}$ ). Soil texture was characterized by quantifying the fractions of clay $(<0.002 \mathrm{~mm})$, silt $(0.002-0.05$ $\mathrm{mm})$, fine sand $(0.05-0.2 \mathrm{~mm})$, coarse sand $(0.2-2 \mathrm{~mm})$, and total sand $(0.05-2 \mathrm{~mm})$ (unit \% of soil weight). We did not quantify nitrogen levels due to the highly volatile nature of nitrogen; 
171 its concentration changes quickly during sample storage due to the activity of soil bacteria, and

172 freezing the samples in our remote sampling localities was not feasible. All analyses were

173 commissioned from EMBRAPA Ocidental (Brazil), following the protocol described in

174 Donagema et al. (2011). Afterwards, we used the mean of the three soil samples from the same 175 plot to obtain a representative value for the measurement of each variable for each plot.

\subsection{DNA EXTRACTION, AMPLIFICATION, AND SEQUENCING}

178

179

180

181

182

The detailed laboratory procedures are described in Ritter et al. (2018). Briefly, we extracted soil and litter using the PowerMax ${ }^{\circledR}$ Soil DNA Isolation Kit (MO BIO Laboratories, USA) following the manufacturer's instructions. The amplification of 16S was performed by Macrogen (Republic of Korea) following standard protocols, and sequencing was performed using the Illumina MiSeq $2 \times 300$ platform. For metabarcoding of the $18 \mathrm{~S}$ gene, sequencing preparation was performed at the laboratory of the University of Gothenburg as described in Ritter et al. (2018) and the amplicons were sequenced at SciLifeLab (Stockholm, Sweden) using an Illumina MiSeq 2x250 machine.

\subsection{SEQUENCE ANALYSES}

We used the USEARCH/UPARSE v9.0.2132 Illumina paired reads pipeline (Edgar, 2013) to filter out poor-quality sequences, de-replicate and sort reads by abundance, and remove singletons. We inferred operational taxonomic units (OTU) at the 97\% sequence similarity level as usually used for OTU clustering (meaning that sequences differing by more than $3 \%$ are considered to belong to different OTUs; Stackebrandt and Goebel, 1994; Blaxter et al., 2005). We used the SINA v1.2.10 for ARB SVN (revision 21008; Pruesse, Peplies, and Glöckner, 
194 2012) taxonomic reference dataset for both markers and used SILVAngs 1.3 for taxonomic

195 assignments (Quast et al., 2013).

196

\subsection{CONSTRUCTION OF CORRECTED OTU TABLES}

198

199

200

201

202

203

204

205

206

207

208

209

210

211

212

213

214

215

216

11

Presence/absence analyses - PCR biases, variation in the copy number of $16 \mathrm{~S} / 18 \mathrm{~S}$ genes per cell/genome, as well as differences in size and biomass across the targeted organisms can compromise a straightforward interpretation of OTU reads as an abundance measure (Elbrecht and Leese, 2015; Pawluczyk et al., 2015). Since the number of observed OTUs is dependent on the number of reads, we first rarefied all samples to the lowest number of reads obtained from any one plot $(22,209$ for $16 \mathrm{~S}$ and 25,144 for $18 \mathrm{~S}$; Fig S1). One sample containing only 1,359 reads was excluded from the $18 \mathrm{~S}$ data analysis prior to rarefaction to avoid having to downsize the other samples to such a low number of reads (McMurdie and Holmes, 2014). The OTU richness of each plot was computed after rarefaction using the function "rarefy" in the package vegan v. 2.4-3 (Oksanen et al., 2007) in R v3.3.2 (R Development Core Team, 2017). We subsequently transformed the rarefied OTU tables to presence/absence for both prokaryote (16S) and eukaryote (18S) data.

Abundance analyses Despite known limitations of methods, read abundances can be meaningful, especially for $16 \mathrm{~S}$. Therefore, we carried out analyses also using abundance data. We calculated true OTU diversity of order $q=1$, which is equivalent to the exponential of the Shannon entropy (Jost, 2006). It can be interpreted as the effective number of OTUs, i.e. the number of OTUs in an idealised community where the geometric mean of the proportional OTU abundances is the same as in the original sample, but all OTUs are equally abundant (Tuomisto, 
217 2010). The effective number of OTUs is more robust against biases arising from uneven

218 sampling depth than the simple number of OTUs, so for diversity we used the unrarefied read

219 counts as OTU abundance. However, the results were virtually identical when we used the

220 rarefied OTU table (correlation $=1$ for both $16 \mathrm{~S}$ and $18 \mathrm{~S}$ ). For the remaining abundance-based

221 analyses, we transformed read counts using the "varianceStabilizingTransformation" function in

222 DESeq2 (Love et al., 2014) as suggested by McMurdie and Holmes (2014). This transformation

223 normalizes the count data with respect to sample size (number of reads in each sample) and

224 variances, based on fitted dispersion-mean relationships (Love et al., 2014).

Preparation of environmental data - We first normalised all soil variables to zero mean and unit variance using the "scale" function of vegan. We then performed two principal component analyses (PCAs) to reduce the number of variables. The first PCA used the chemical soil properties, i.e. all variables based on concentrations of elements. The second PCA used the physical soil properties, i.e. grain size classes. We input missing sand, silt, and clay information

232 for three plots, based on regression weights from the observed data using the mice v. $2.30 \mathrm{R}$ 233 package (Buuren and Groothuis-Oudshoorn, 2011) before performing the PCAs. We used the first axis of each PCA (explaining $66 \%$ and $65 \%$ of the total variation, respectively) in the subsequent analyses. Given the expected importance of soil organic carbon content (Nielson et al., 2011) and pH (Lauber et al., 2009), we used these as independent variables. 
238 Hypothesis testing - For all analyses we used pH, organic carbon, chemical PC1, and physical

239 PC1 as explanatory variables. All analyses were carried out using presence-absence data and

240 relative abundance data in parallel: in the case of diversity, richness corresponds to presence-

241 absence data and effective number of OTUs to relative abundance data. Overall, each kind of

242 analysis was carried out eight times: one for each of the eight possible combinations of organism

243 group (prokaryote or $16 \mathrm{~S}$, eukaryote or $18 \mathrm{~S}$ ), substrate (soil, litter) and abundance measure

244 (presence-absence, proportional abundance).

Do OTU diversities reflect physical or chemical soil properties? To address the first question, we performed Bayesian general linear models (GLM), as implemented in the R-INLA

v. 17.6.20 R package (Rue et al., 2009). The response variables were the eight different variants of OTU diversity in turn, and in each case the soil properties were used as explanatory variables. We tested the effect of spatial auto-correlation by comparing analyses of standard GLMs with GLM analysis using stochastic partial differential equations (SPDE) that explicitly consider 252 spatial correlation.

Do OTU community turnovers reflect differences in physical and chemical soil properties? To address the second question, we performed multiple regressions on dissimilarity matrices (MRM), as implemented in the function "MRM" of the R package ecodist v.2.0.1 (Goslee and Urban, 2007). The response variables were dissimilarity matrices based on the eight different variants of OTU turnover (as calculated using the Jaccard dissimilarity) in turn. In each case, the explanatory variables were four distance matrices based on soil properties and one geographical 
260 distance matrix (all calculated using Euclidean distances). Statistical significance of the

261 regression coefficients was determined with 10,000 permutations. Additionally, we used

262 variance partitioning analysis based in dissimilarity matrixes to quantify the unique and shared

263 contributions of each of the explanatory variables to explaining variance in the response distance

264 matrix (Tuomisto and Ruokolainen 2006).

Does OTU diversity of the litter layer predict the OTU diversity of the underlying soil? To address the third question, we analysed the relationship between litter and soil OTU richness and diversity for prokaryotes (16S) and eukaryotes (18S) using a linear regression model (the $\mathrm{lm}$ function in R).

Are OTU community turnover patterns in the litter layer similar to those in the underlying soil?

To address the fourth question, we first performed non-metric multidimensional scaling (NMDS) ordinations as implemented in the metaMDS function in the $\mathrm{R}$ package vegan. Compositional dissimilarity was quantified with the Jaccard dissimilarity index. Ordinations based on the same organism group and abundance data type but different substrates were then compared. Next, we used the Permutational Analysis of Variance (PERMANOVA) to assess whether substrate type has an effect on community composition. Finally, we illustrated which were the dominant taxonomic groups (phyla or kingdom) with bar-plots. As with the other questions, all analyses were repeated for all possible combinations of organism group (prokaryotes or $16 \mathrm{~S}$ and eukaryotes or $18 \mathrm{~S}$ ) and abundance data type (presence-absence and proportional abundance, in the bar-plots we used the rarefied abundance data). 
282 Additional $\mathrm{R}$ packages we used for data curation and visualization were tidyverse v. 1.1.1

283 (Wickham, 2017), Hmisc v. 4.0-3 (Harrell Jr., 2016), ggfortify v. 0.1.0 (Tang et al., 2016),

284 gridExtra v. 2.2.1 (Auguie, Antonov and Auguie, 2016), ggplot2 (Wickham, 2016), entropart 285 (Marcon and Hérault, 2015), broom v.0.4.4 (Robinson, 2018), and viridis v. 0.4.0 (Garnier, 286 2016). Scripts for all analyses are provided in the supplementary material.

3. Results

289

3.1. OTU DIVERSITY AND TURNOVER IN RELATION TO SOIL PROPERTIES (RESEARCH QUESTIONS 1 AND 2)

In the physical soil data PCA, large values on the first PC were associated with coarse texture (coarse sand fraction loading 0.52, total sand fraction loading 0.55) and small values with fine texture (silt loading -0.45 , clay loading -0.38; Table S2). The flooded forests (igapós and várzeas) generally had fine-textured soils (negative values of PC1). The unflooded forests (terrafirme and campinas) were more widely distributed along PC1, with some plots having similar values with várzeas and igapós (Fig. 2A). In the chemical soil data PCA, large values on the first PC were associated with poor soils. The most negative loading was -0.35 for the sum of exchangeable bases (SB), and the largest positive loading was 0.29 for aluminium saturation index (Table S3). The habitat types were not well separated along the first axis of the chemical PCA, as most plots of all habitat types had poor soils (large values of PC1) and just a few scattered várzea and igapó plots had more cation-rich soils (small values of PC1; Fig. 2B). 
303 In general, organic carbon and $\mathrm{pH}$ had the strongest effects on OTU diversity. This was the case

304 both for prokaryotes and eukaryotes, for richness and effective number of OTUs and for soil and

305 litter (Table 1). In addition, PC1 of chemical soil properties was an important predictor for

306 prokaryotic OTU richness in the soil and litter, with stronger effect in soil than in litter, and for

307 prokaryotic effective number of OTUs just in soil. For eukaryotes, soil texture had an important

308 effect on OTU diversity, albeit different on each substrate: positive for soil and negative for litter

309 (Table 1). Overall, soil properties had strong effects on OTU diversity in litter.

311 OTU community turnover was significantly associated with soil properties, especially with

312 organic carbon and $\mathrm{pH}$, which were significant for all communities. The $\mathrm{pH}$ effect was strong for 313 all prokaryote (16S) datasets and for eukaryotes (18S) in soil when relative abundance data were 314 used (Table 2). Organic carbon had the strongest effect for eukaryotes in soil when 315 presence/absence data were used and for eukaryotes in litter with both presence/absence and 316 relative abundance data. Chemical PC1 was significant for prokaryotes in soil (both 317 presence/absence and relative abundance) and for eukaryotes in litter when presence/absence 318 data were used. Texture PC1 was significant only for eukaryotes in litter (both presence/absence 319 and relative abundance; Table 2). Geographical distance was a significant explanatory factor for

320 all datasets, but as closer places usually are more environmentally similar, we cannot separate the 321 effect of spatial correlation from soil property effects.

323 A moderate percentage of the variation in Jaccard dissimilarities was explained by soil 324 physicochemical properties in the presence/absence data, for prokaryotes (31\% in soil and 35\% 
325 in litter; Fig. 3). For eukaryotes, the total explanatory power of soil physicochemical properties

326 was smaller (12\% in soil and $16 \%$ in litter). For prokaryotes and eukaryotes, the litter

327 communities were more structured by soil characteristics than were the soil communities. All

328 variables explained small but significant proportions of the variance in all communities and

329 showed some weak but significant interactions considering presence/absence matrices (Fig. 3)

330 and a similar, strong proportion of the variance in abundance data (Fig. S2). Organic carbon had

331 the strongest effect in all substrates and for both organism groups (ranging from 0.03 for

332 eukaryotes in soil through 0.05 for eukaryotes in litter to 0.08 for prokaryotes in both soil and 333 litter).

3.2. SiMILARITIES IN OTU DIVERSITY AND TURNOVER PATTERNS BETWEEN LITTER AND SOIL 336 (RESEARCH QUESTIONS 3-4)

We found a weak positive regression between OTU richness of prokaryotes in litter and in soil

338 (adj. $\mathrm{R}^{2}=0.25, \mathrm{p}<0.001$; Fig. 4A) and between the effective number of prokaryote OTUs in 339 litter and in soil (adj. $\mathrm{R}^{2}=0.1, \mathrm{p}=0.03$; Fig. 4B). For eukaryotes, the corresponding correlations 340 were not significant (Fig. 4C and 4D). The plot "CXNCAMP3" had very low soil OTU richness, 341 and excluding this data point strengthened the correlation of OTU richness between soil and litter 342 for prokaryotes (to adj. $\mathrm{R}^{2}=0.46, \mathrm{p}<0.001$; Fig. S3A), but not for eukaryotes (Fig. S3B).

344 The OTU communities in litter and in soil tended to be separated in the NMDS ordination space, 345 although there was some overlap especially for the igapó plots (Fig. 5). The PERMANOVA test 346 indicated weak but significant effects (all $\mathrm{p}<0.001$ ) of substrate type on compositional 
347 dissimilarities of both prokaryotes $\left(\mathrm{R}^{2}=0.06, \mathrm{~F}=5.83\right.$, for presence/absence data and $\mathrm{R}^{2}=0.07$,

$348 \mathrm{~F}=6.7$, for abundance data) and eukaryotes $\left(\mathrm{R}^{2}=0.03, \mathrm{~F}=2.8\right.$ for presence/absence data and $\mathrm{R}^{2}$

$349=0.04, F=3.74$, for abundance data). Habitat type had an even stronger effect on the

350 compositional dissimilarities of both prokaryotes $\left(\mathrm{R}^{2}=0.17, \mathrm{~F}=5.48\right.$, for presence/absence data

351 and $\mathrm{R}^{2}=0.18, \mathrm{~F}=5.68$, for abundance data) and eukaryotes $\left(\mathrm{R}^{2}=0.1, \mathrm{~F}=2.8\right.$, for

352 presence/absence data and $\mathrm{R}^{2}=0.1, \mathrm{~F}=2.98$, for abundance data). Taxonomic composition at

353 the phylum and kingdom (for fungi) level was similar in litter and in soil both for prokaryotes

354 and for eukaryotes (Fig. 6). However, in prokaryotes Actinobacteria is the second most abundant

355 phylum in litter when taking into account the relative abundances (Fig. 6).

\section{Discussion}

\subsection{SOIL PREDICTORS OF OTU DIVERSITY AND COMMUNITY TURNOVER}

In this study, we tested the impact of physicochemical soil properties on the OTU diversity (richness and effective number of OTUs) and community turnover of prokaryotes and eukaryotes in soil and litter across Brazilian Amazonia. We found that that the soil properties we quantified had variable effects on OTU diversity and community turnover for litter and soil, and the effect varied between prokaryotic and eukaryotic organisms. The variable with the highest explanatory power was overall organic carbon for both prokaryotes and eukaryotes. OTU diversity and community turnover were better explained by soil properties in litter than in soil.

367 Considering the results from the linear models, in general organic carbon and $\mathrm{pH}$ were the 
368 strongest factors in explaining soil prokaryotic and litter and soil eukaryotic diversity. Our results

369 show a positive correlation between soil $\mathrm{pH}$ and OTU diversity, which is expected since much of

370 the soils in Amazonia are acidic. For instance, for soil samples, Lauber et al. (2009) found pH to

371 be the main factor in explaining bacterial phylogenetic diversity and phylogenetic composition,

372 where soils with $\mathrm{pH}$ between 4.5 and 8 had the highest bacterial diversity. Tropical forests with

373 high macro-organismic diversity had soil with $\mathrm{pH}<4.5$ and had the lowest bacterial diversity

374 (Lauber, 2009). In our samples, $\mathrm{pH}$ was overall low and its variation was moderate, from 3.65 to

5.14, thereby in less acid soil we found highest OTU diversity considering both richness and effective number of OTUs.

We also found that variation in $\mathrm{pH}$ was significant for all community turnovers, and that it was the strongest variable in explaining community turnover for prokaryotes (in both soil and litter) and for eukaryotes in soil (Table 2). However, we found that $\mathrm{pH}$ had no effect on prokaryote richness in litter (Table1). The consistent effect of $\mathrm{pH}$ for prokaryotes and eukaryotes in the soil, with significant effect in community turnover and diversity, but inconsistent effect in litter support the findings of Gregorich et al. (2016), who found no correlation of soil properties and litter decomposition. This points to the independence of the environmental factors regulating each substrate.

We found significant effects of variation in organic carbon on all community turnovers with the strongest effect for eukaryotes in litter (Table 2). Additionally, we found a negative correlation 
390 previously been found to have an effect on carbon sequestration (Wagg et al., 2013). However,

391 the relationship between soil biodiversity and carbon has varied across studies (Nielson et al.,

392 2011). Furthermore, Fierer et al. (2012) and de Lima Brossi et al. (2014) found that soil organic

393 matter was related to microbial community composition in several different vegetation types.

394 The negative correlation between soil organic carbon content and OTU diversity reported here

395 might be related to high nutrient turnover in high-diversity soil/litter, keeping the carbon stock

396 locked in aboveground biomass. Our results support the findings of Wall et al. (2008), who

397 found a positive influence of the richness of soil biota on decomposition rates in wet tropical

398 environments. Along the same line, Wagg et al. (2013) found that soil diversity and soil

399 community composition are related through nutrient cycling. Decreases in soil diversity and the

400 related changes in community composition alter the communities' capacity to break down

401 organic matter and recycle nutrients, slowing down the return of nutrients to the above-ground

402 communities (Wardle et al., 2004). These findings stress the complex nature of carbon-diversity

403 dynamics and the plant-soil feedback loop mediated by soil biota (Mangan et al., 2010). They

404 furthermore highlight a connection between decomposition rates and biodiversity in Amazonia

405 that should be better explored.

406

407 We found that prokaryotic community turnover is more strongly related with environmental 408 distance than eukaryotic community turnover which is mostly dominated by fungi (fungi correspond to $35 \%$ of OTU richness and $50 \%$ of OTU relative abundance in our eukaryotic data;

410 Fig. 6C \& 6D). This is in agreement with the results from a global bacterial and fungi soil 411 sampling (Bahram et al., 2018). In our results, environmental distances explained only a limited 412 percentage of OTU community turnover (31-35\% for prokaryotes and $12-16 \%$ for eukaryotes; 
413 Fig. 3). This suggests that other factors, such as precipitation and bacterial-fungal antagonistic 414 interactions (Bahram et al., 2018), also need to be considered to better understand the community 415 turnover these organisms.

417 Biotic and abiotic interactions jointly determine soil properties, making it important to consider 418 environmental and biological interactions between variables. Indeed, our variance analysis reveals several co-variances between soil properties, such as $\mathrm{pH}$ and organic carbon and physical and chemical properties. Although these interactions were weak, this analysis is important for 421 providing a better understanding of the study system. Considering physicochemical soil properties, we had a partial separation of the major environmental types by the properties of their soils. It is in agreement with previous studies, which report an association of soil types and habitats in Amazonia (e.g. Falesi, 1984; Prance, 1996). The soil texture (first axis of the physical PCA) was well separated by the habitat types of flooded forests (igapós and várzeas), whereas terra-firme and campinas were more spread in physical properties. On the other hand, the first axis of chemical PCA was less well separated for flooded areas (igapós and várzeas). This result was expected since there is a variation within habitat types, especially flooded forests (Kalliola et 429 al., 1993; Tuomisto, Ruokolainen and Yli-Halla, 2003; Tuomisto et al., 2014, 2016). Furthermore, terra-firme forests have been reported to vary in soil nutrients (e.g. Tuomisto, Ruokolainen and Yli-Halla, 2003; Tuomisto et al., 2014, 2016; Fine et al., 2005), consistent with the variation observed in our plots. However, due to the limited sampling in our studies, the 433 variation we detected was small (Fig. 2B). Our finding that soil texture is similar among the 434 flooded environments (várzeas and igapós) and that soil texture was an important factor for 435 eukaryote diversity (both soil and litter) is consistent with the previously reported community 
436 similarity among these environmental types based on the data from the same samples (Ritter et

437 al., 2018).

438

439

\subsection{CONTRASTING LITTER AND SOIL DIVERSITY}

440 The correlations between soil and litter OTU diversity (richness and the effective number of

441 OTUs) were significant for prokaryotes but not for eukaryotes. This is congruent with previous

442 reports that showed the independence of litter accumulation from properties of the underlying 443 soils (Gregorich et al., 2016).

We expected a difference in taxonomic composition between litter and soil communities, with microbes dominating the soil (e.g. Bates et al., 2013; Mahé et al. 2017) and plant and nematode

447 OTUs dominating the litter due to it mainly being composed of leaves and roots. However, we found the highest plant (Chloroplastida) richness and abundance in the soil samples. Furthermore, unlike Porazinska et al. (2012) who found a dominance of nematodes in the litter of tropical forests, we found very similar proportions of nematode OTUs in soil and litter, with the highest richness and abundance in the soil (Fig. 6C and 6D). This pattern of no clear taxonomic differences between soil and litter layers is consistent with respect to all dominant groups at the phylum and kingdom levels (Fig. 6). This suggests that, on the Amazon basin scale, the taxonomic composition at higher levels (phylum and kingdom) is consistent between litter and soil with some variation in abundance for some groups, such as Arthropoda and Chloroplastida 456 for eukaryotes and Actinobacteria, Bacterioides and Chloroflexi for prokaryotes (Fig. 6). 
458 Interestingly, the phyla that dominated our samples were only partly the same as those found 459 dominant in a large global dataset (Fig. 6A and 6B; Delgado-Baquerizo et al., 2018). While we 460 also found Proteobacteria to be the most frequent phylum considering both presence/absence and 461 relative abundance, the second most frequent phylum was Chloroflexi in presence/absence data 462 for soil and litter and abundance for soil in our samples, while this Chloroflexi was only the $5^{\text {th }}$ 463 most abundant in the global dataset. Actinobacteria, the second most abundant phylum in the 464 global database, was in our data the second most abundant phylum just for abundance in litter 465 samples. Moreover, the rank-abundance distribution of the most dominant phyla was more even 466 in our tropical sample than in the global sample, with Proteobacteria accounting for just over $46720 \%$ of all reads (versus almost $40 \%$ in the global dataset) and eight phyla representing more 468 than $5 \%$ of relative frequency each ( $>70 \%$ of relative frequency) versus only four phyla in 469 Delgado-Baquerizo et al. (2018). Taken together, these differences highlight the need for more 470 studies across the Amazon basin to better characterize the taxonomic composition.

472 The OTU community compositions of both prokaryotes and eukaryotes were better explained by 473 habitat type (terra firme, várzea, igapó, campina) than they were by substrate type (soil, litter), 474 which was expected since both substrates should share a large number of organisms. The 475 substrate types were weakly differentiated at the OTU level, but we could not observe any 476 difference at the phylum or kingdom levels for presence-absence and only a small difference for 477 abundance data (Fig. 6). For instance, fungi usually dominate eukaryotic soil communities in any 478 environment, including tropical forests (Tedersoo et al., 2017), but the dominant fungal taxa 
479 (OTU) may vary considerably even at local and sub-local scales (Urbanová et al., 2015). In a 480 study conducted in the western parts of the Czech Republic, similar results for bacteria and fungi

481 were found: the phylum level indicated the same taxonomic groups as dominant in soils and 482 litter, but there were striking differences at the OTU level in these substrates (Urbanová et al., 483 2015).

\section{Conclusions}

In this study, we found OTU diversities to be related between soil and litter in prokaryotes, but not in eukaryotes. We also found that physicochemical soil properties can predict soil and litter diversity in Amazonia to some extent. In particular, we found a positive correlation for $\mathrm{pH}$ and a negative correlation for soil organic carbon content with respect to prokaryotic and eukaryotic OTU diversity. Furthermore, we found a significant effect of variation in soil organic carbon content on community turnover. In general, our results stress the complexity of soil-biodiversity relationships, and hence the importance of considering multiple factors and their interactions in the characterization of biodiversity patterns. Soil biodiversity is crucial for carbon cycling in terrestrial ecosystems, and our results suggest that additional studies to better understand the relationship between diversity (above and belowground) and carbon cycles may help modelling carbon deposition and biodiversity patterns.

\section{Acknowledgements}

We thank Anna Ansebo, Sven Toresson, and Ylva Heed for laboratory and administrative 
500

501

502

503

504

505

506

507

508

509

510

511

512

513

514

515

516

517

518

519

520

assistance; Mats Töpel for help with bioinformatics; and Quiterie Haenel for help with the DNA extractions and fruitful discussions. We thank Hans ter Steege for advice on sampling localities and experimental design. We are grateful to members of our research group for discussions and suggestions. Additional computational analyses were run at the University of Gothenburg bioinformatics cluster at the Department of Biological and Environmental Sciences (http://albiorix.bioenv.gu.se/).

\section{References}

Auguie, B., Antonov, A. and Auguie, M. B. 2016. Package 'gridExtra'.

Bahram, M., Hildebrand, F., Forslund, S. K., Anderson, J. L., Soudzilovskaia, N. A., Bodegom, P. M., Bengtsson-Palme, J., Anslan, S., Coelho, L. P., Harend, H., Huerta-Cepas, J., Medema, M. H., Maltz, M. R., Mundra, S., Olsson, P. A., Pent, M., Põlme, S., Sunagawa, S., Ryberg, M., Tedersoo, L. and Bork, P. 2018. Structure and function of the global topsoil microbiome. Nature, pp. 1476-4687. DOI: 10.1038/s41586-018-0386-6.

Baldeck, C.A., Tupayachi, R., Sinca, F., Jaramillo, N. and Asner, G.P., 2016. Environmental drivers of tree community turnover in western Amazonian forests. Ecography, 39(11), pp.10891099. DOI: $10.1111 /$ ecog.01575.

Bardgett, R.D. and Van Der Putten, W.H., 2014. Belowground biodiversity and ecosystem functioning. Nature, 515(7528), pp.505-511. DOI: 10.1038/nature13855.

Barnes, C.J., Maldonado, C., Frøslev, T.G., Antonelli, A. and Rønsted, N., 2016. Unexpectedly high beta-diversity of root-associated fungal communities in the Bolivian Andes. Frontiers in 
521

522

523

524

525

526

527

528

529

530

531

532

533

534

535

536

537

538

539

540

Microbiology, 7. DOI: 10.3389/fmicb.2016.01377.

Basset, Y., Cizek, L., Cuénoud, P., Didham, R.K., Guilhaumon, F., Missa, O., Novotny, V.,

Ødegaard, F., Roslin, T., Schmidl, J. and Tishechkin, A.K., 2012. Arthropod diversity in a tropical forest. Science, 338(6113), pp.1481-1484. DOI: 10.1126/science.1226727.

Bates, S.T., Clemente, J.C., Flores, G.E., Walters, W.A., Parfrey, L.W., Knight, R. and Fierer, N., 2013. Global biogeography of highly diverse protistan communities in soil. The ISME Journal, 7(3), p.652. DOI: 10.1038/ismej.2012.147.

Blaxter, M., Mann, J., Chapman, T., Thomas, F., Whitton, C., Floyd, R. and Abebe, E., 2005.

Defining operational taxonomic units using DNA barcode data. Philosophical Transactions of the Royal Society B: Biological Sciences, 360(1462), pp.1935-1943. DOI: $10.1098 /$ rstb.2005.1725

Buckley, D.H. and Schmidt, T.M., 2001. Environmental factors influencing the distribution of rRNA from Verrucomicrobia in soil. FEMS Microbiology Ecology,35(1), pp.105-112. DOI: 10.1111/j.1574-6941.2001.tb00793.x.

Buuren, S. and Groothuis-Oudshoorn, K., 2011. mice: Multivariate imputation by chained equations in R. Journal of Statistical Software, 45(3).

Cámara-Leret, R., Tuomisto, H., Ruokolainen, K., Balslev, H. and Munch Kristiansen, S., 2017. Modelling responses of western Amazonian palms to soil nutrients. Journal of Ecology, 105(2), pp.367-381.

de Lima Brossi, M.J., Mendes, L.W., Germano, M.G., Lima, A.B. and Tsai, S.M., 2014. 
541 Assessment of bacterial bph gene in Amazonian Dark Earth and their adjacent soils. PLOS

542 ONE, 9(6), p.e99597. DOI: 10.1371/journal.pone.0099597.

543 Delgado-Baquerizo, M., Oliverio, A.M., Brewer, T.E., Benavent-González, A., Eldridge, D.J.,

544 Bardgett, R.D., Maestre, F.T., Singh, B.K. and Fierer, N., 2018. A global atlas of the dominant

545 bacteria found in soil. Science, 359(6373), pp.320-325. DOI: 10.1126/science.aap9516.

546 Donagema, G.K., De Campos, D.B., Calderano, S.B., Teixeira, W.G. and Viana, J.M., 2011.

547 Manual de métodos de análise de solo. Embrapa Solos-Documentos (INFOTECA-E).

548 Edgar, R.C., 2013. UPARSE: highly accurate OTU sequences from microbial amplicon 549 reads. Nature Methods, 10(10), pp.996-998. DOI: 10.1038/nmeth.2604.

550 Elbrecht, V. and Leese, F., 2015. Can DNA-based ecosystem assessments quantify species 551 abundance? Testing primer bias and biomass - sequence relationships with an innovative 552 metabarcoding protocol. PLOS ONE, 10(7), p.e0130324. DOI: 10.1371/journal.pone.0130324.

553 Falesi, I. C. 1984. Estado atual de conhecimento dos solos da Amazônia Brasileira. - In:

554 Simpósio do Trópico Umido, Belém, 1984. Embrapa-CPATU, Documentos, 36: pp. 168-191.

555 Falkowski, P.G., Fenchel, T. and Delong, E.F., 2008. The microbial engines that drive Earth's 556 biogeochemical cycles. Science, 320(5879), pp.1034-1039. DOI: 10.1126/science.1153213.

557 Faoro, H., Alves, A.C., Souza, E.M., Rigo, L.U., Cruz, L.M., Al-Janabi, S.M., Monteiro, R.A., 558 Baura, V.A. and Pedrosa, F.O., 2010. Influence of soil properties on the diversity of bacteria in 559 the Southern Brazilian Atlantic Forest. Applied and Environmental Microbiology, 76(14), 560 pp.4744-4749. DOI: 10.1128/AEM.03025-09. 
561 Fierer, N., Strickland, M.S., Liptzin, D., Bradford, M.A. and Cleveland, C.C., 2009. Global 562 patterns in belowground communities. Ecology Letters, 12(11), pp.1238-1249. 563 DOI: 10.1111/j.1461-0248.2009.01360.x.

564 Fierer, N., Leff, J.W., Adams, B.J., Nielsen, U.N., Bates, S.T., Lauber, C.L., Owens, S., Gilbert, 565 J.A., Wall, D.H. and Caporaso, J.G., 2012. Cross-biome metagenomic analyses of soil microbial 566 communities and their functional attributes. Proceedings of the National Academy of 567 Sciences, 109(52), pp.21390-21395. DOI: 10.1073/pnas.1215210110.

Fine, P.V., Daly, D.C., Muñoz, G.V., Mesones, I. and Cameron, K.M., 2005. The contribution of 569 edaphic heterogeneity to the evolution and diversity of Burseraceae trees in the western 570 Amazon. Evolution, 59(7), pp.1464-1478. DOI: 10.1554/04-745

Friesen, M.L., Porter, S.S., Stark, S.C., Von Wettberg, E.J., Sachs, J.L. and Martinez-Romero, E., 2011. Microbially mediated plant functional traits. Annual Review of Ecology, Evolution, and Systematics, 42, pp.23-46. DOI: 10.1146/annurev-ecolsys-102710-145039.

Garnier, S., 2016. viridis: Default color maps from 'matplotlib’[Software].

575 Goslee, S.C. and Urban, D.L., 2007. The ecodist package for dissimilarity-based analysis of 576 ecological data. Journal of Statistical Software, 22(7), pp.1-19.

577 Gregorich, E.G., Janzen, H., Ellert, B.H., Helgason, B.L., Qian, B., Zebarth, B.J., Angers, D.A., 578 Beyaert, R.P., Drury, C.F., Duguid, S.D. and May, W.E., 2017. Litter decay controlled by 579 temperature, not soil properties, affecting future soil carbon. Global Change Biology, 23(4), 580 pp.1725-1734. DOI: doi.org/10.1111/gcb.13502. 
581 Harrell Jr, F.E. and Dupont, C., 2008. Hmisc: harrell miscellaneous. R package version, 3(2).

582 Higgins, M.A., Ruokolainen, K., Tuomisto, H., Llerena, N., Cardenas, G., Phillips, O.L.,

583 Vásquez, R. and Räsänen, M., 2011. Geological control of floristic composition in Amazonian

584 forests. Journal of Biogeography,38(11), pp.2136-2149. DOI: $\quad 10.1111 / \mathrm{j} .1365-$ $585 \quad 2699.2011 .02585 . x$.

586 Hinsinger, P., Bengough, A.G., Vetterlein, D. and Young, I.M., 2009. Rhizosphere: biophysics, 587 biogeochemistry and ecological relevance. Plant and Soil, 321(1-2), pp.117-152.

IBGE 2004. Mapa de Vegetação do Brasil 1:5,000,000. - IBGE - Instituto Brasileiro de 589 Geografia e Estatística.

Jost, L., 2006. Entropy and diversity. Oikos, 113(2), pp.363-375. DOI: 10.1111/j.2006.00301299.14714.x.

Junk, W.J., Piedade, M.T.F., Schöngart, J., Cohn-Haft, M., Adeney, J.M. and Wittmann, F., 593 2011. A classification of major naturally-occurring Amazonian lowland wetlands. Wetlands, 31(4), pp.623-640. DOI: 10.1007/s13157-011-0190-7.

Kalliola, R., Puhakka, M., Salo, J., Linna, A. and Räsänen, M., 1993. Mineral nutrients in fluvial sediments from the Peruvian Amazon. Catena,20(3), pp.333-349. DOI: 10.1016/0341597 8162(93)90009-E.

598 Kuramae, E.E., Yergeau, E., Wong, L.C., Pijl, A.S., Van Veen, J.A. and Kowalchuk, G.A., 2012.

599 Soil properties more strongly influence soil bacterial communities than land-use type. FEMS 600 Microbiology Ecology, 79(1), pp.12-24. DOI: 10.1111/j.1574-6941.2011.01192.x. 
601 Lauber, C.L., Hamady, M., Knight, R. and Fierer, N., 2009. Pyrosequencing-based assessment of 602 soil $\mathrm{pH}$ as a predictor of soil bacterial community structure at the continental scale. Applied and 603 Environmental Microbiology, 75(15), pp.5111-5120. DOI: 10.1128/AEM.00335-09.

604 Laurance, S.G., Laurance, W.F., Andrade, A., Fearnside, P.M., Harms, K.E., Vicentini, A. and 605 Luizão, R.C., 2010. Influence of soils and topography on Amazonian tree diversity: a 606 landscape-scale study. Journal of Vegetation Science, 21(1), pp.96-106. DOI: 10.1111/j.1654607 1103.2009.01122.x.

608

609

610

611

612

613

614

615

616

617

618

619

620 621 journal.pcbi.1003531. 0550-8.

Love, M.I., Huber, W. and Anders, S., 2014. Moderated estimation of fold change and dispersion for RNA-seq data with DESeq2. Genome Biology, 15(12), p.550. DOI: 10.1186/s13059-014-

Mahé, F., de Vargas, C., Bass, D., Czech, L., Stamatakis, A., Lara, E., Singer, D., Mayor, J., Bunge, J., Sernaker, S. and Siemensmeyer, T., 2017. Parasites dominate hyperdiverse soil protist communities in Neotropical rainforests. Nature Ecology \& Evolution, 1(4), p.0091.

Mangan, S.A., Schnitzer, S.A., Herre, E.A., Mack, K.M., Valencia, M.C., Sanchez, E.I. and Bever, J.D., 2010. Negative plant-soil feedback predicts tree-species relative abundance in a tropical forest. Nature, 466(7307), pp.752-755. DOI: 10.1038/nature09273.

Marcon, E. and Hérault, B., 2015. entropart: An R package to measure and partition diversity. Journal of Statistical Software, 67(8). DOI: 10.18637/jss.v067.i08.

McMurdie, P.J. and Holmes, S., 2014. Waste not, want not: why rarefying microbiome data is inadmissible. PLoS Computational Biology, 10(4), p.e1003531. DOI: 10.1371/ 
622 Myster, R.W., 2016. The physical structure of forests in the Amazon Basin: a review. The 623 Botanical Review, 82(4), pp.407-427. DOI: 10.1007/s12229-016-9174-x.

624 Myster, R.W., 2017. A comparison of the forest soils in the Peruvian Amazon: Terra firme, 625 palm, white sand and igap. Journal of Soil Science and Environmental Management, 8(7), 626 pp.130-134. DOI: 10.5897/JSSEM2017.0644.

627 Navarrete, A.A., Kuramae, E.E., De Hollander, M., Pijl, A.S., Van Veen, J.A. and Tsai, S.M., 628 2013. Acidobacterial community responses to agricultural management of soybean in Amazon 629 forest soils. FEMS Microbiology Ecology, 83(3), pp.607-621. DOI: 10.1111/1574-6941.12018.

630 Nielsen, U.N., Ayres, E., Wall, D.H. and Bardgett, R.D., 2011. Soil biodiversity and carbon 631 cycling: a review and synthesis of studies examining diversity-function relationships. European 632 Journal of Soil Science, 62(1), pp.105-116. DOI: 10.1111/j.1365-2389.2010.01314.x.

633 Oksanen, J., Kindt, R., Legendre, P., O’hara, B., Stevens, M.H.H. 2007. The vegan 634 package. Community ecology package, 10, pp.631-637.

635 Osborne, C.A., Zwart, A.B., Broadhurst, L.M., Young, A.G. and Richardson, A.E., 2011. The 636 influence of sampling strategies and spatial variation on the detected soil bacterial communities 637 under three different land-use types. FEMS Microbiology Ecology, 78(1), pp.70-79. DOI: 638 10.1111/j.1574-6941.2011.01105.x.

639 Pawluczyk, M., Weiss, J., Links, M.G., Aranguren, M.E., Wilkinson, M.D. and Egea-Cortines, 640 M., 2015. Quantitative evaluation of bias in PCR amplification and next-generation sequencing 641 derived from metabarcoding samples. Analytical and Bioanalytical Chemistry, 407(7), pp.1841642 1848. DOI: 10.1007/s00216-014-8435-y. 
643 Peres-Neto, P.R., Legendre, P., Dray, S. and Borcard, D., 2006. Variation partitioning of species

644 data matrices: estimation and comparison of fractions. Ecology, 87(10), pp. 2614-2625.

645 Porazinska, D.L., Giblin-Davis, R.M., Powers, T.O. and Thomas, W.K., 2012. Nematode spatial 646 and ecological patterns from tropical and temperate rainforests. PLOS ONE, 7(9), p.e44641. 647 DOI: 10.1371/journal.pone.0044641.

648 Prance GT., 1996. Islands in Amazonia. Philosophical Transactions of the Royal Society of 649 London. B, 29(1341), pp. 823-33. DOI: 10.1098/rstb.1996.0077

650 Pruesse, E., Peplies, J. and Glöckner, F.O., 2012. SINA: accurate high-throughput multiple 651 sequence alignment of ribosomal RNA genes. Bioinformatics, 28(14), pp.1823-1829. DOI: 652 10.1093/bioinformatics/bts252.

653 Quast, C., Pruesse, E., Yilmaz, P., Gerken, J., Schweer, T., Yarza, P., Peplies, J. and Glöckner, 654 F.O., 2012. The SILVA ribosomal RNA gene database project: improved data processing and 655 web-based tools. Nucleic Acids Research, 41(D1), pp.D590-D596. DOI: 10.1093/nar/gks1219.

656 QGIS Development Team, 2012. QGIS Geographic Information System. Open Source 657 Geospatial Foundation Project.

658 R Development Core Team. 2017. R: a language environment for statistical computing. Vienna: 659 R Foundation for Statistical Computing. (http://www.r-project.org/). Accessed 15/02/2017.

660 Ritter, C.D., Zizka, A., Barnes, C., Nilsson, R.H., Roger, F., and Antonelli, A., (Accepeted). 661 Locality or habitat? Exploring predictors of biodiversity in Amazonia. Ecography. DOI: 662 10.1111/ecog.03833. 
663 Robinson, D., 2017. broom: Convert statistical analysis objects into tidy data frames. $R$ package 664 version 0.4.4.

665 Rue, H., Martino, S., Lindgren, F., Simpson, D., Riebler, A. and Krainski, E.T., 2009. INLA: 666 functions which allow to perform a full Bayesian analysis of structured additive models using 667 Integrated Nested Laplace Approximation. R package version 0.0.

668 Stackebrandt, E. and Goebel, B.M., 1994. Taxonomic note: a place for DNA-DNA reassociation 669 and 16S rRNA sequence analysis in the present species definition in bacteriology. International 670 Journal of Systematic and Evolutionary Microbiology,44(4), pp.846-849. DOI: $671 \quad 10.1099 / 00207713-44-4-846$.

672 Stajich, J.E., Berbee, M.L., Blackwell, M., Hibbett, D.S., James, T.Y., Spatafora, J.W. and 673 Taylor, J.W., 2009. Primer--The Fungi. Current Biology: CB, 19(18), p.R840. 674 DOI: 10.1016/j.cub.2009.07.004.

675 Taberlet, P., Coissac, E., Pompanon, F., Brochmann, C. and Willerslev, E., 2012. Towards 676 next-generation biodiversity assessment using DNA metabarcoding. Molecular Ecology, 21(8), 677 pp.2045-2050. DOI: 10.1111/j.1365-294X.2012.05470.x.

678 Tang, Y., Horikoshi, M. and Li, W., 2016. ggfortify: Unified interface to visualize statistical 679 results of popular R Packages. The R Journal, 8(2), pp.478-489.

680 Tedersoo, L., Bahram, M., Põlme, S., Kõljalg, U., Yorou, N.S., Wijesundera, R., Ruiz, L.V., 681 Vasco-Palacios, A.M., Thu, P.Q., Suija, A. and Smith, M.E., 2014. Global diversity and 682 geography of soil fungi. Science, 346(6213), p.1256688. DOI: 10.1126/science.1256688. 
683 Tedersoo, L., Bahram, M., Cajthaml, T., Põlme, S., Hiiesalu, I., Anslan, S., Harend, H., Buegger, 684 F., Pritsch, K., Koricheva, J. and Abarenkov, K., 2016. Tree diversity and species identity effects 685 on soil fungi, protists and animals are context dependent. The ISME Journal, 10(2), pp.346-362. 686 DOI: $10.1038 /$ ismej.2015.116.

687 Tedersoo, L., Bahram, M., Puusepp, R., Nilsson, R.H. and James, T.Y., 2017. Novel soil688 inhabiting clades fill gaps in the fungal tree of life. Microbiome, 5(1), p.42. DOI: $68910.1186 / \mathrm{s} 40168-017-0259-5$.

690 Tuomisto, H. 2010. A diversity of beta diversities: straightening up a concept gone awry. Part 1. 691 Defining beta diversity as a function of alpha and gamma diversity. Ecography 33: 2-22. DOI: $69210.1111 / \mathrm{j} .1600-0587.2009 .05880 . \mathrm{x}$

693 Tuomisto, H., Ruokolainen, K. and Yli-Halla, M., 2003. Dispersal, environment, and floristic 694 variation of western Amazonian forests. Science, 299(5604), pp.241-244. DOI: $69510.1126 /$ science.1078037.

696 Tuomisto, H., Poulsen, A.D., Ruokolainen, K., Moran, R.C., Quintana, C., Celi, J., and Cañas, G. 697 2003. Linking floristic patterns with soil heterogeneity and satellite imagery in Ecuadorian 698 Amazonia. Ecological Applications 13: 352-371. DOI: 10.1890/1051699 0761(2003)013[0352:LFPWSH]2.0.CO;2

700 Tuomisto, H., Zuquim, G. and Cárdenas, G., 2014. Species richness and diversity along edaphic 701 and climatic gradients in Amazonia. Ecography, 37(11), pp.1034-1046.

702 Tuomisto, H., Moulatlet, G.M., Balslev, H., Emilio, T., Figueiredo, F.O., Pedersen, D. and

703 Ruokolainen, K., 2016. A compositional turnover zone of biogeographical magnitude within 
704 lowland Amazonia. Journal of Biogeography, 43(12), pp.2400-2411.

705 Urbanová, M., Šnajdr, J. and Baldrian, P., 2015. Composition of fungal and bacterial 706 communities in forest litter and soil is largely determined by dominant trees. Soil Biology and 707 Biochemistry, 84, pp.53-64. DOI: 10.1016/j.soilbio.2015.02.011.

708 Vogel, T.M., Simonet, P., Jansson, J.K., Hirsch, P.R., Tiedje, J.M., Van Elsas, J.D., Bailey, M.J.,

709 Nalin, R. and Philippot, L., 2009. TerraGenome: a consortium for the sequencing of a soil 710 metagenome. Nature Reviews Microbiology, 7, 252. DOI: 10.1038/nrmicro2119

711 Wagg, C., Bender, S.F., Widmer, F. and van der Heijden, M.G., 2014. Soil biodiversity and soil 712 community composition determine ecosystem multifunctionality. Proceedings of the National 713 Academy of Sciences, 111(14), pp.5266-5270. DOI: 10.1073/pnas.1320054111.

714 Wall, D. H., Bradford, M. A., S T, J., Trofymow, J. A., Behan-Pelletier, V., Bignell, D. E., 715 Wardle, D.A., Bardgett, R.D., Klironomos, J.N., Setälä, H., Van Der Putten, W.H. and Wall, 716 D.H., 2004. Ecological linkages between aboveground and belowground 717 biota. Science, 304(5677), pp.1629-1633. DOI: 10.1126/science.1094875.

718 Wickham, H., 2016. ggplot2: elegant graphics for data analysis. Springer.

719 Wickham, H., 2017. tidyverse. R package version, 1.1.1. 
722

723 - DNA sequences: BioSample accessions SAMN09081679-SAMN09081756; NCBI SRA:

724 PRJNA464362, Bioproject 410658.

725 - Final DNA sequence assembly uploaded as online supplementary items

726 - Sampling locations, soil physical-chemical data, OTU tables, and R scripts: included as

727 supplementary material.

728

729 


\section{Table $\mathbf{1}$ (on next page)}

Soil effects on OTU richness and Shannon diversity:

The importance of soil properties differed between taxon, substrate and diversity metrics. Carbon content and pH were important in most of the cases. The table shows the coefficients of each predictor in four Bayesian general multivariate regression model using Stochastic Partial Differential Equations (SPDE) that explicitly consider spatial correlation, modelling OTU richness and effective number of OTUs dependent on soil properties for eukaryotes and prokaryotes in litter and soil, respectively. As the organic carbon content and pH are important variables for soil biota, we use them as independent variables. Bold indicates important predictor variables (credible intervals not crossing zero). 
1 Table 1: Soil effects on OTU richness and Shannon diversity: The importance of soil

2 properties differed between taxon, substrate and diversity metrics. Carbon content and $\mathrm{pH}$ were

3 important in most of the cases. The table shows the coefficients of each predictor in four

4 Bayesian general multivariate regression model using Stochastic Partial Differential Equations

5 (SPDE) that explicitly consider spatial correlation, modelling OTU richness and effective

6 number of OTUs dependent on soil properties for eukaryotes and prokaryotes in litter and soil,

7 respectively. As the organic carbon content and $\mathrm{pH}$ are important variables for soil biota, we use

8 them as independent variables. Bold indicates important predictor variables (credible intervals

9 not crossing zero).

\begin{tabular}{|c|c|c|c|c|c|c|c|c|}
\hline \multirow[b]{2}{*}{ Taxon } & \multirow[b]{2}{*}{ Substrate } & \multirow[b]{2}{*}{ Predictor } & \multicolumn{3}{|c|}{ OTU richness } & \multicolumn{3}{|c|}{ Effective number of OTUs } \\
\hline & & & Mean & $\begin{array}{c}0.025 \\
\text { quantile }\end{array}$ & $\begin{array}{c}0.975 \\
\text { quantile }\end{array}$ & Mean & $\begin{array}{c}0.025 \\
\text { quantile }\end{array}$ & $\begin{array}{c}0.975 \\
\text { quantile }\end{array}$ \\
\hline \multirow{10}{*}{ 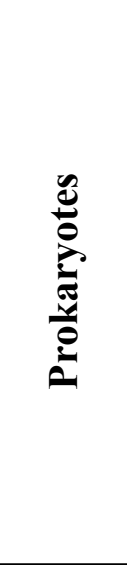 } & \multirow{5}{*}{$\overline{\bar{\theta}}$} & \multirow{5}{*}{$\begin{array}{l}\text { Intercept } \\
\text { pH } \\
\text { Carbon } \\
\text { Chemical } \\
\text { Physical }\end{array}$} & 6.14 & 2.31 & 9.95 & 6.07 & 2.03 & 10.43 \\
\hline & & & 0.22 & 0.16 & 0.27 & 0.22 & 0.17 & 0.27 \\
\hline & & & -0.13 & -0.19 & -0.08 & -0.15 & -0.20 & -0.10 \\
\hline & & & -0.08 & -0.14 & -0.02 & -0.08 & -0.14 & -0.02 \\
\hline & & & 0.02 & 0.00 & 0.04 & 0.02 & -0.01 & 0.04 \\
\hline & \multirow{5}{*}{ 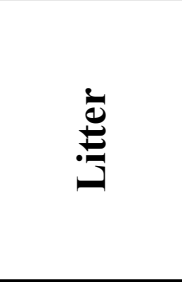 } & Intercept & 4.14 & -4.78 & 12.65 & 5.04 & -3.97 & 13.71 \\
\hline & & & 0.03 & -0.03 & 0.08 & 0.05 & 0.00 & 0.10 \\
\hline & & Carbon & -0.23 & -0.28 & -0.17 & -0.21 & -0.26 & -0.16 \\
\hline & & Chemical & -0.07 & -0.12 & -0.01 & -0.05 & -0.11 & 0.01 \\
\hline & & Physical & 0.13 & 0.10 & 0.15 & 0.12 & 0.10 & 0.15 \\
\hline \multirow{10}{*}{ 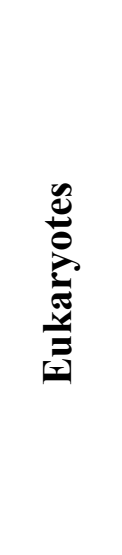 } & \multirow{5}{*}{$\overline{\bar{\sigma}}$} & Intercept & 3.28 & -7.36 & 13.39 & 3.22 & -6.49 & 13.22 \\
\hline & & & 0.30 & 0.22 & 0.38 & 0.33 & 0.25 & 0.41 \\
\hline & & Carbon & -0.36 & -0.46 & -0.26 & -0.36 & -0.46 & -0.27 \\
\hline & & Chemical & -0.08 & -0.20 & 0.04 & -0.05 & -0.17 & 0.06 \\
\hline & & Physical & 0.11 & 0.07 & 0.15 & 0.10 & 0.07 & 0.14 \\
\hline & \multirow{5}{*}{ 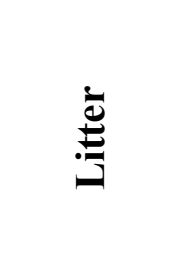 } & Intercept & 4.93 & -10.81 & 19.82 & 6.07 & -10.14 & 21.34 \\
\hline & & & 0.24 & 0.15 & 0.34 & 0.26 & 0.16 & 0.35 \\
\hline & & Carbon & -0.22 & -0.32 & -0.13 & -0.23 & -0.32 & -0.14 \\
\hline & & Chemical & -0.01 & -0.12 & 0.10 & 0.00 & -0.10 & 0.11 \\
\hline & & Physical & -0.14 & -0.19 & -0.09 & -0.15 & -0.20 & -0.10 \\
\hline
\end{tabular}


11 


\section{Table 2 (on next page)}

Association between environmental distance and community turnover:

Community dissimilarity is significantly associated with geographical and soil environmental distance for eukaryote and prokaryote communities in soil and litter. The Multiple Regressions were based on the geographical distance, Euclidean distance matrices of soil properties and community Jaccard dissimilarity indexes. Geographic distances were significant for all communities turnover; however, as geographical closest places are usually more environmental similar, we cannot separate the effect of soil properties from the spatial correlation. All community turnovers were significant with 10,000 permutations ( $p<0.001$ ) with the follow $R^{2}$ : prokaryote soil $\left(R^{2}=0.36\right.$ for presence/absence and $R^{2}=0.36$ for relative abundance), prokaryote litter $\left(R^{2}=0.39\right.$ for presence/absence and $R^{2}=0.35$ for relative abundance), eukaryote soil $\left(R^{2}=0.21\right.$ for presence/absence and $R^{2}=0.20$ for relative abundance) and eukaryote litter $\left(R^{2}=0.32\right.$ for presence/absence and $R^{2}=0.30$ for relative abundance). 
1 Table 2: Association between environmental distance and community turnover: Community

2 dissimilarity is significantly associated with geographical and soil environmental distance for

3 eukaryote and prokaryote communities in soil and litter. The Multiple Regressions were based on

4 the geographical distance, Euclidean distance matrices of soil properties and community Jaccard

5 dissimilarity indexes. Geographic distances were significant for all communities turnover;

6 however, as geographical closest places are usually more environmental similar, we cannot

7 separate the effect of soil properties from the spatial correlation. All community turnovers were

8 significant with 10,000 permutations $(\mathrm{p}<0.001)$ with the follow $\mathrm{R}^{2}$ : prokaryote soil $\left(\mathrm{R}^{2}=0.36\right.$

9 for presence/absence and $\mathrm{R}^{2}=0.36$ for relative abundance), prokaryote litter $\left(\mathrm{R}^{2}=0.39\right.$ for

10 presence/absence and $\mathrm{R}^{2}=0.35$ for relative abundance), eukaryote soil $\left(\mathrm{R}^{2}=0.21\right.$ for

11 presence/absence and $\mathrm{R}^{2}=0.20$ for relative abundance) and eukaryote litter $\left(\mathrm{R}^{2}=0.32\right.$ for

12 presence/absence and $\mathrm{R}^{2}=0.30$ for relative abundance).

\begin{tabular}{|c|c|c|c|c|c|c|}
\hline \multirow[b]{2}{*}{ Taxon } & \multirow[b]{2}{*}{ Substrate } & \multirow[b]{2}{*}{ Predictor } & \multicolumn{2}{|c|}{ Presence/absence } & \multicolumn{2}{|c|}{ Relative abundance } \\
\hline & & & coefficients & $\begin{array}{c}\mathbf{p} \\
\text { value }\end{array}$ & coefficients & $\underset{\text { value }}{\mathbf{p}}$ \\
\hline \multirow{12}{*}{ 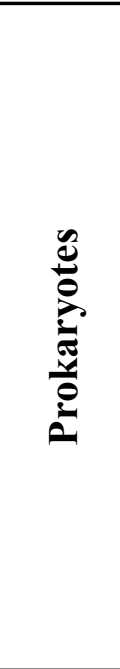 } & \multirow{6}{*}{ ") } & Intercept & -24.28 & 1.00 & -8.63 & 1.00 \\
\hline & & Geo_dist & 0.15 & 0.00 & 0.15 & 0.00 \\
\hline & & Chemical & 0.23 & 0.00 & 0.21 & 0.01 \\
\hline & & Physical & 0.18 & 0.01 & 0.17 & 0.01 \\
\hline & & & 0.30 & 0.00 & 0.34 & 0.00 \\
\hline & & Carbon & 0.20 & 0.01 & 0.16 & 0.03 \\
\hline & \multirow{6}{*}{ 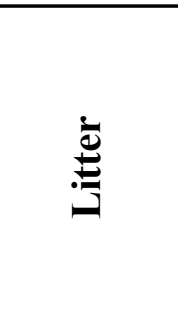 } & Intercept & -60.59 & 1.00 & -37.45 & 1.00 \\
\hline & & Geo_dist & 0.19 & 0.00 & 0.20 & 0.00 \\
\hline & & Chemical & 0.18 & 0.00 & 0.11 & 0.09 \\
\hline & & Physical & 0.16 & 0.00 & 0.19 & 0.00 \\
\hline & & & 0.32 & 0.00 & $\mathbf{0 . 3 3}$ & 0.00 \\
\hline & & Carbon & 0.32 & 0.00 & 0.28 & 0.00 \\
\hline \multirow{4}{*}{ 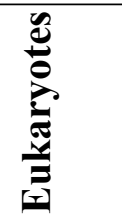 } & \multirow{4}{*}{ "ृ̈ } & Intercept & 43.54 & 1.00 & 59.63 & 1.00 \\
\hline & & Geo_dist & 0.09 & 0.06 & 0.10 & 0.03 \\
\hline & & Chemical & 0.12 & 0.16 & 0.11 & 0.21 \\
\hline & & Physical & 0.15 & 0.04 & 0.16 & 0.03 \\
\hline
\end{tabular}




\begin{tabular}{l|l|l|cc|cc}
\hline & pH & $\mathbf{0 . 2 2}$ & $\mathbf{0 . 0 0}$ & $\mathbf{0 . 2 4}$ & $\mathbf{0 . 0 0}$ \\
& Carbon & $\mathbf{0 . 2 9}$ & $\mathbf{0 . 0 0}$ & $\mathbf{0 . 2 3}$ & $\mathbf{0 . 0 1}$ \\
\hline \multirow{4}{*}{} & Intercept & -8.86 & 1.00 & 10.65 & 1.00 \\
& Geo_dist & $\mathbf{0 . 1 5}$ & $\mathbf{0 . 0 0}$ & $\mathbf{0 . 1 7}$ & $\mathbf{0 . 0 0}$ \\
& Chemical & $\mathbf{0 . 2 6}$ & $\mathbf{0 . 0 0}$ & $\mathbf{0 . 2 2}$ & $\mathbf{0 . 0 0}$ \\
& Physical & 0.09 & 0.13 & 0.05 & 0.40 \\
& Ph & $\mathbf{0 . 1 9}$ & $\mathbf{0 . 0 0}$ & $\mathbf{0 . 2 4}$ & $\mathbf{0 . 0 0}$ \\
& pH & $\mathbf{0 . 3 3}$ & $\mathbf{0 . 0 0}$ & $\mathbf{0 . 2 9}$ & $\mathbf{0 . 0 0}$ \\
\hline
\end{tabular}

13 


\section{Figure 1}

Study area and sampling locations.

Inset panels show details of each locality. A: Benjamin Constant; B: Jaú; C: Jaú, naturally open areas; D: Cuieras; E: Cuieras, naturally open areas; and F: Caxiuanã. The symbols in A-F represent different vegetation types that are linked with different soil properties: circles $=$ open areas; triangles $=$ forest seasonally flooded by black water rivers; squares $=$ unflooded forest; and crosses = forest seasonally flooded by white water rivers. The sampling strategy was designed to cover a wide longitudinal range in Amazonia. The map was constructed using QGIS (2012).

*Note: Auto Gamma Correction was used for the image. This only affects the reviewing manuscript. See original source image if needed for review.

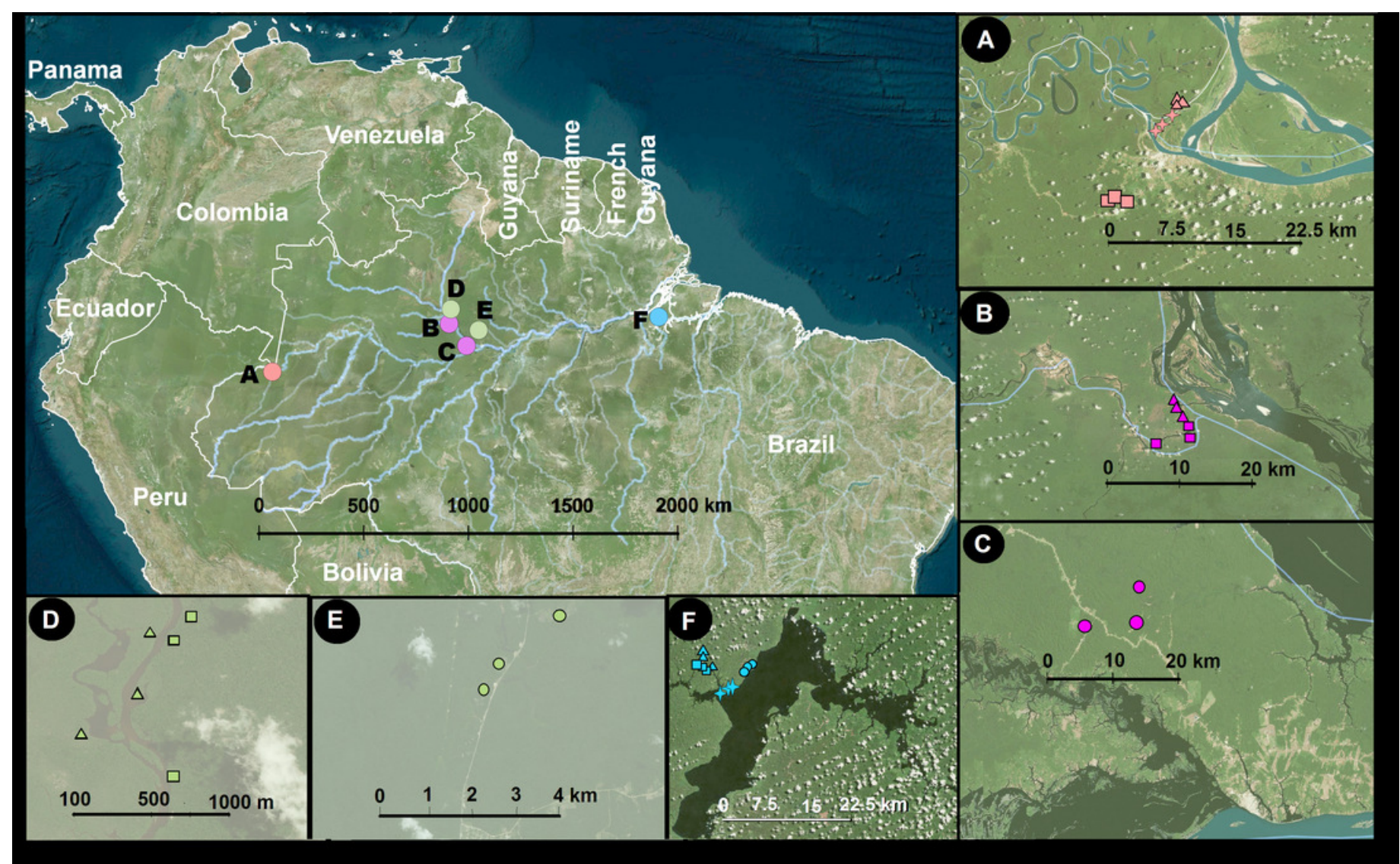




\section{Figure 2}

Physical and chemical soil similarity of sample sites across Amazonia.

The figure shows the study sites - coloured by habitat type - on the first two axes of a Principle Component Analysis for A) physical properties (silt, clay and fine, coarse, and total sand fraction) and B) chemical proprieties (phosphorus [P], exchangeable bases $[\mathrm{Na}, \mathrm{K}, \mathrm{Ca}$, and $\mathrm{Mg}$, the sum of all exchangeable bases [SB], exchangeable aluminium [Al and $\mathrm{H}+\mathrm{Al}$, saturation index by aluminium [m], base saturation index [V], effective cation exchange capacity [t], and cation exchange capacity [T]). The blue rows show the values of each variable loadings in the two firs PCs. For physical PCA we can observe that flooded forest (igapós and várzeas) are associated with negative values in the first PC axis and a more spread distribution of terra-firme and campinas. For chemical PCA there is no separation of flooded forest, but campinas group in most positive values in the first PCA axis followed by terra-firmes.

A) Physical PCA

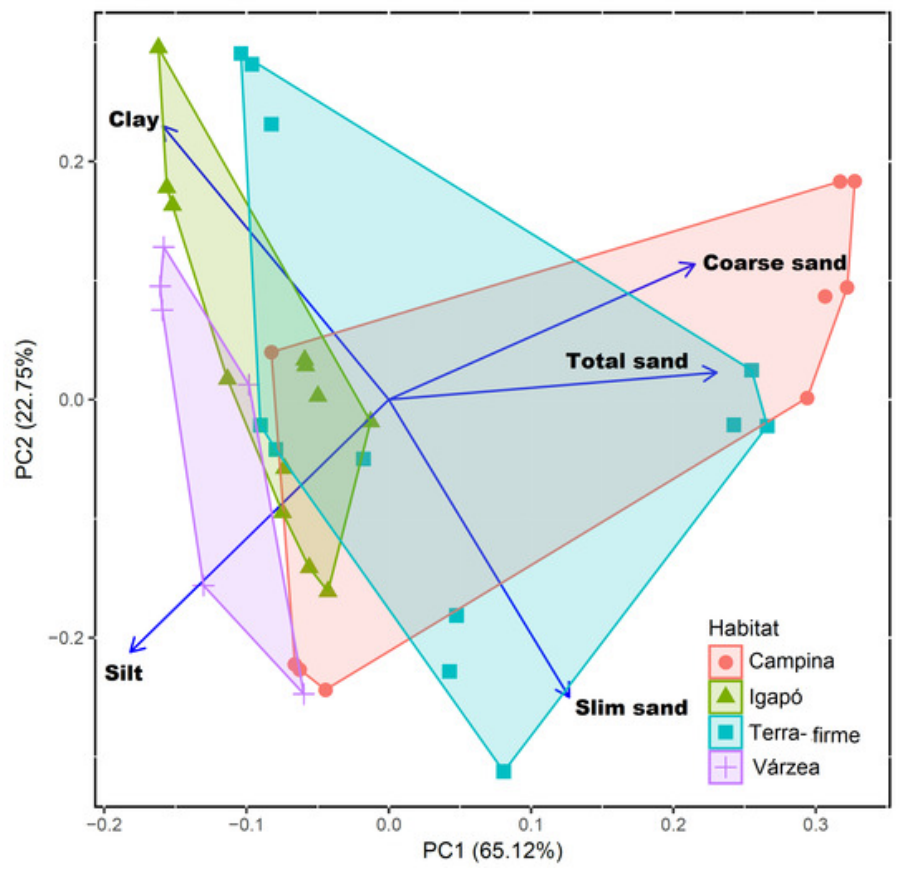

B) Chemical PCA

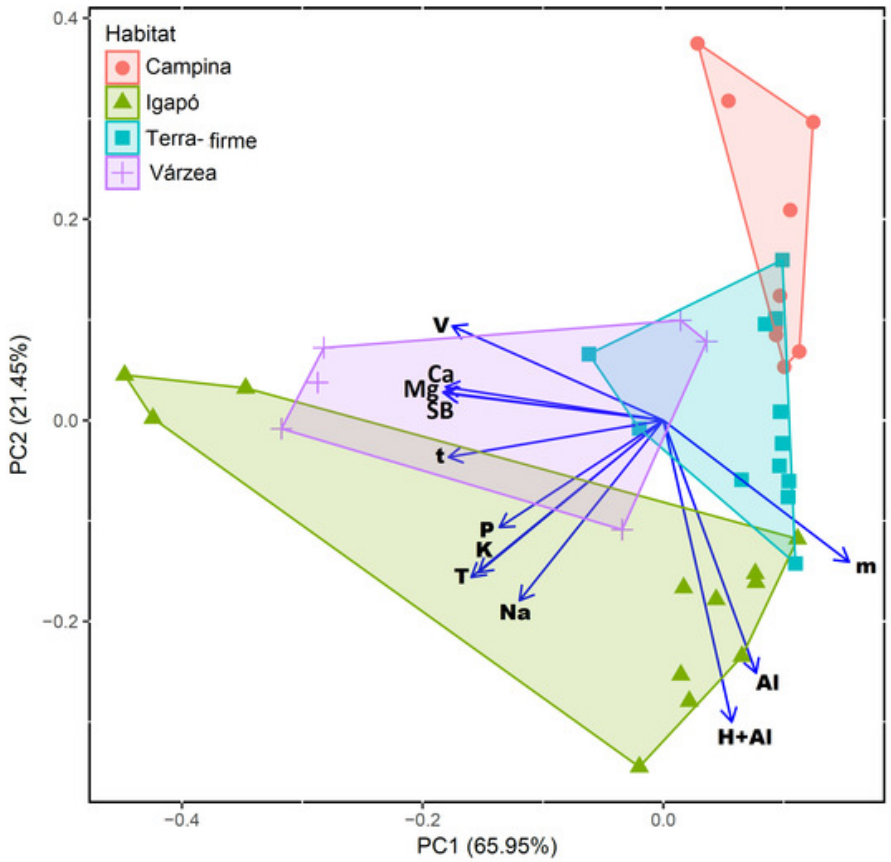




\section{Figure 3}

Variation in OTU community composition in Amazonian soil samples explained by soil characteristics.

Results of the variance partition analysis based on Jaccard dissimilarity distance-based analysis. Small but significant proportions of soil and litter communities vary with soil variables, and a small but significant proportion shows variation shared by soil variables. All values represent the proportion of variation explained by the factor/interaction. Chemical variables are shown in green (based on the first PCA of chemical variables, see Table S3 for details), physical variables in purple (based on first PCA axis of soil texture, see Table S2 for details), $\mathrm{pH}$ in blue, and carbon content in orange. The prokaryote communities are more structured by soil characteristics than are the eukaryote ones. Inside each taxonomic group, the litter communities are more structured by soil characteristics than are the soil communities. 
A) Prokaryote (16S) soil

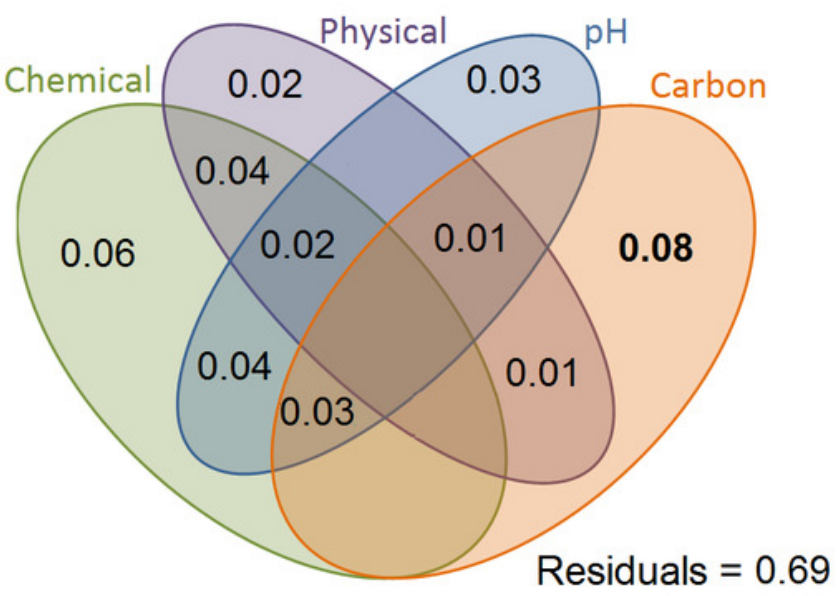

C) Eukaryote (18S) soil

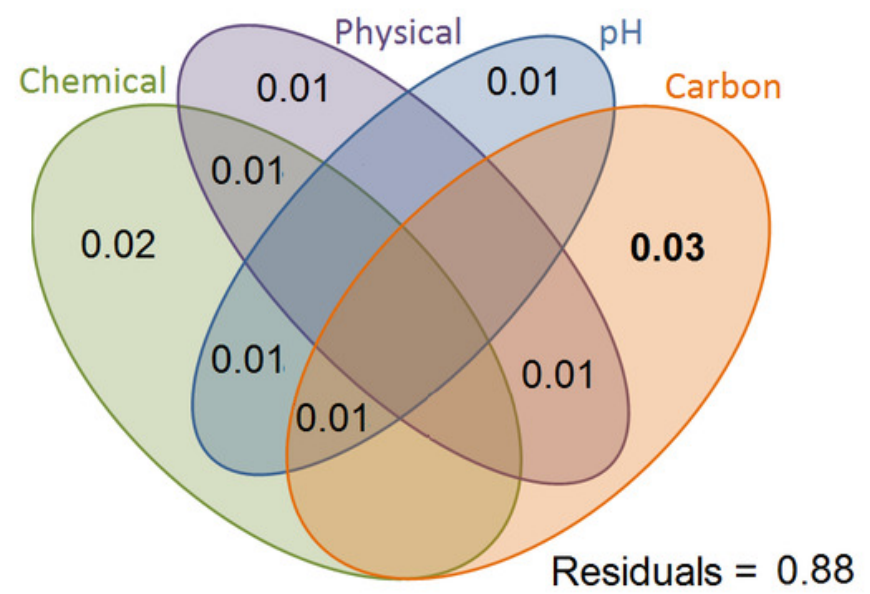

B) Prokaryote (16S) litter

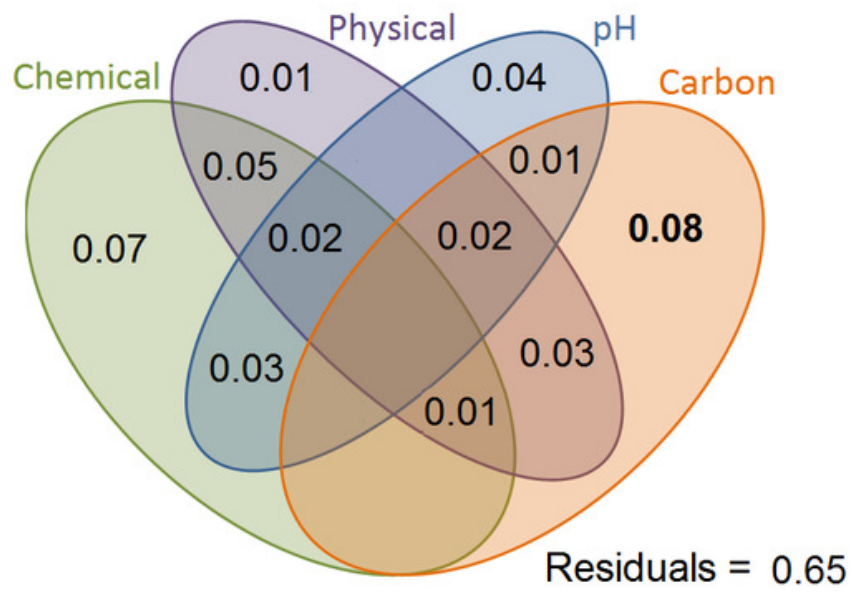

D) Eukaryote (18S) litter

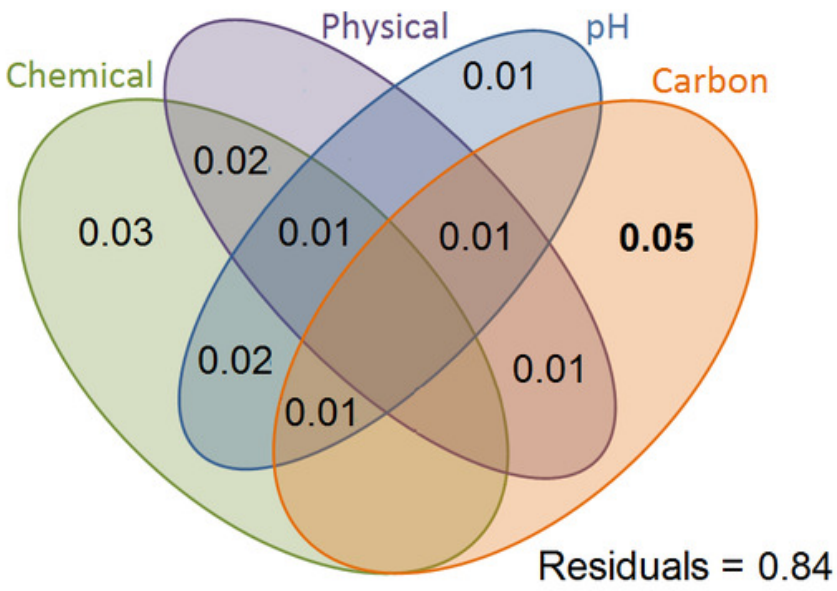




\section{Figure 4}

Relation between OTU diversity in soil and litter

Prokaryotes (16S) are showed in A) OTU richness and B) effective number of OTUs;

eukaryotes (18S) are showed in C) OTU richness and D) effective number of OTUs in the Amazonian soil samples. The blue line shows a linear regression with standard error indicated by the shaded area for significant correlations. The relationship between soil layers (litter vs soil) is weak and differs between taxa, with only prokaryotes showing a significant correlation for richness and effective number of OTUs. This result suggests that it OTU diversity in litter is unsuitable as proxy for the OTU diversity in the soil and vice versa. 
A) Prokaryote (16S) rarefied

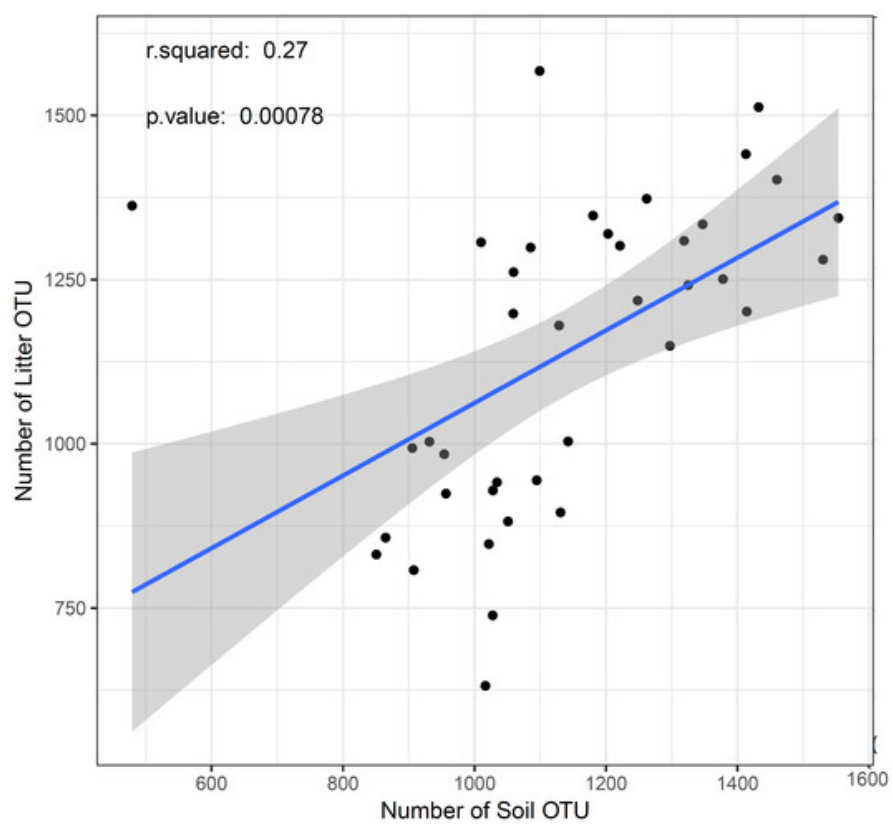

C) Eukaryote (18S) rarefied

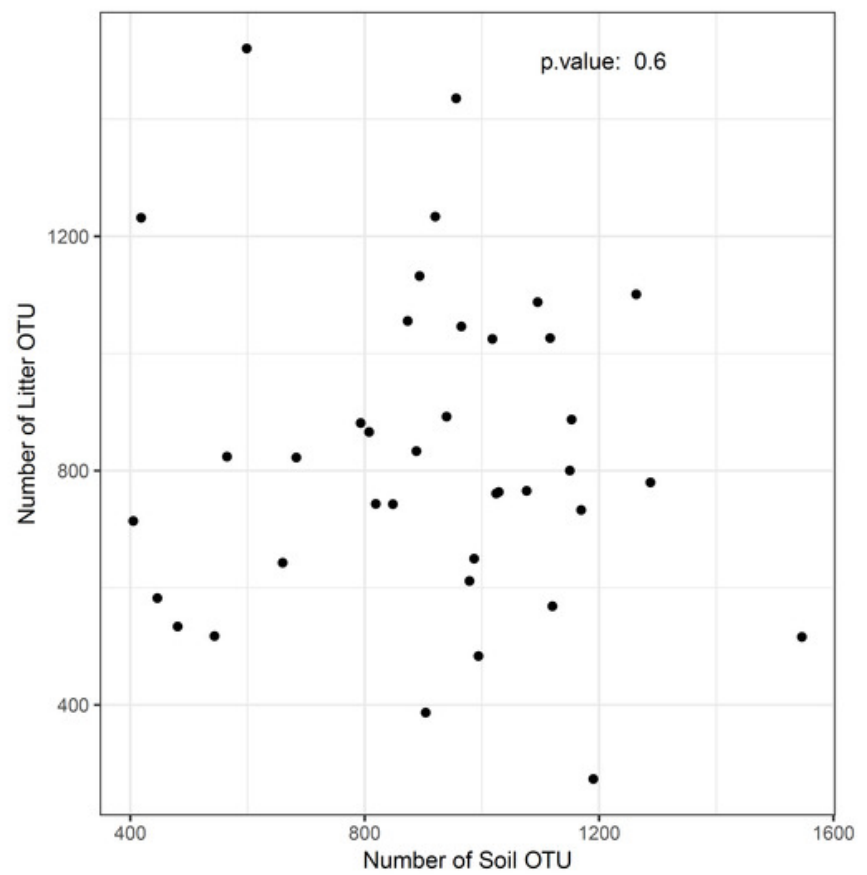

B) Prokaryote (16S) effective number of OTUs

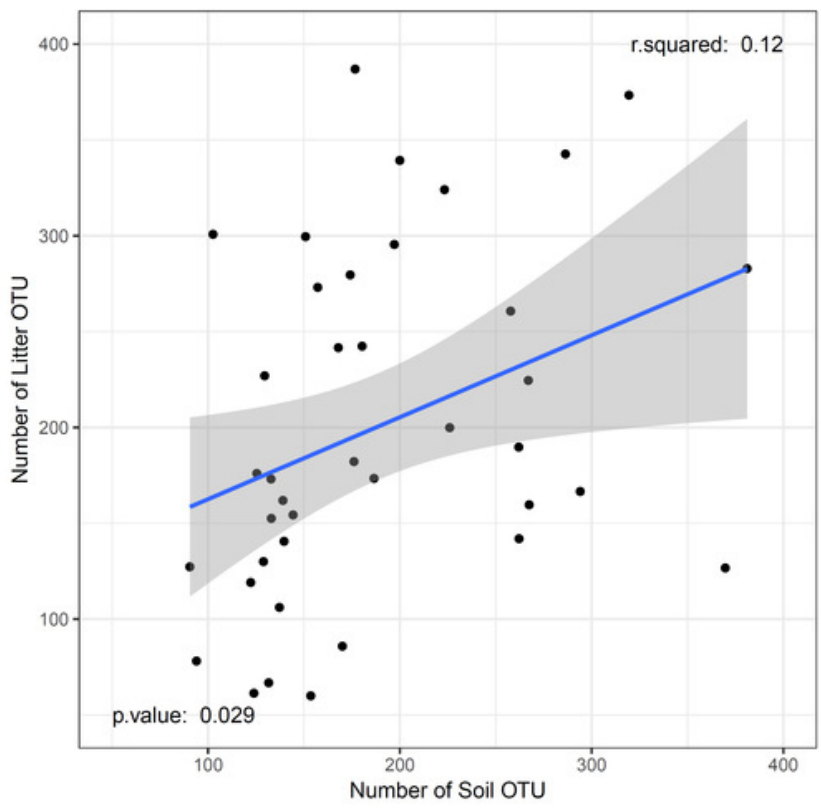

D) Eukaryote (18S) effective number of OTUs

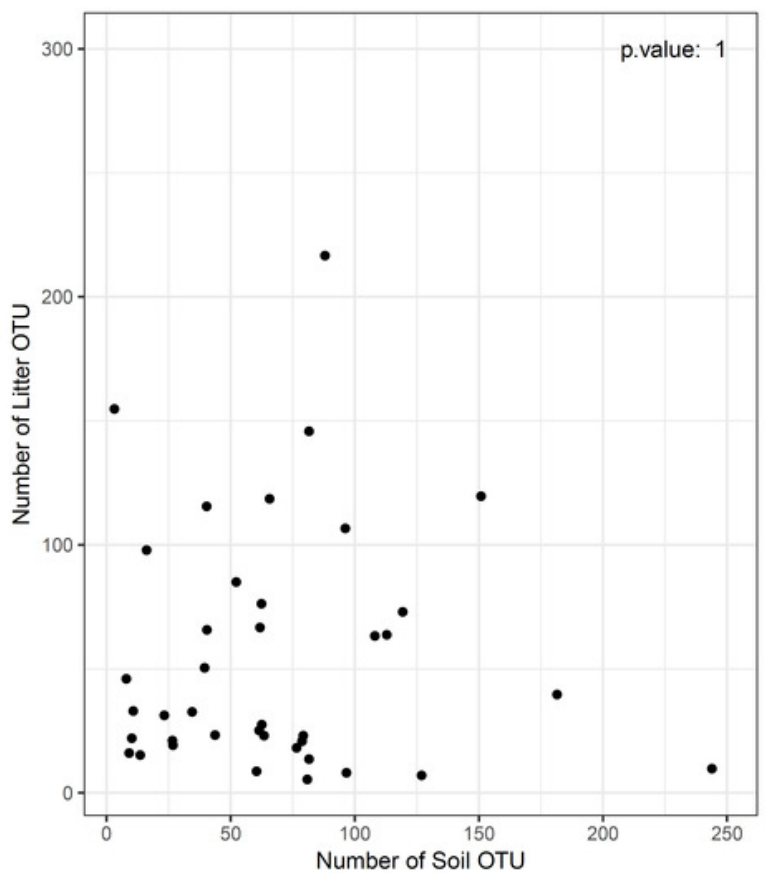




\section{Figure 5}

Community structure related to substrate type (litter and soil) and habitat types.

Visualization of differences in OTU composition (measured with the presence/absence matrixes using Jaccard dissimilarity index in $A$ and $B$; and measured with relative abundance matrixes using Bray-Curtis dissimilarity index) using non-metric multidimensional scaling (NMDS) for A) and C) prokaryotes (16S) and B) and D) eukaryotes (18S). Symbols represent different habitats. Blue represent litter samples and green soil samples. A small but statistically significant (PERMANOVA test) separation between the substrates can be observed along the second ordination axis for both groups of organisms. The strongest and most significant separation is observed between habitat types.
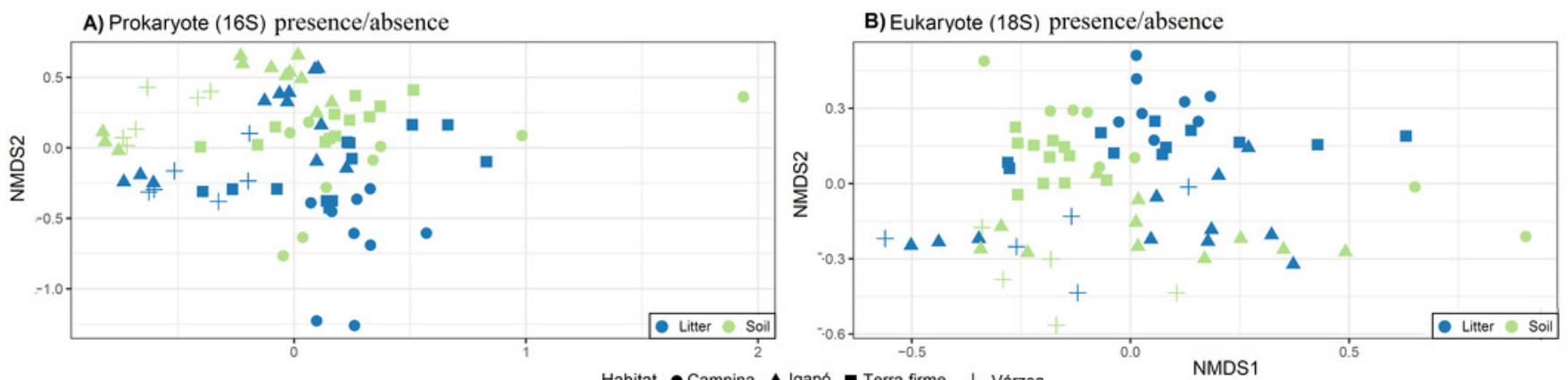

C) Prokaryote (16S) abundance

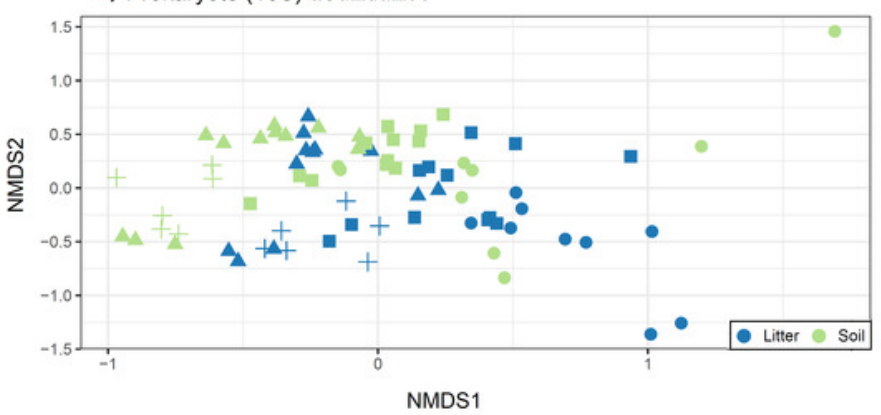

D) Eukaryote (18S) abundance

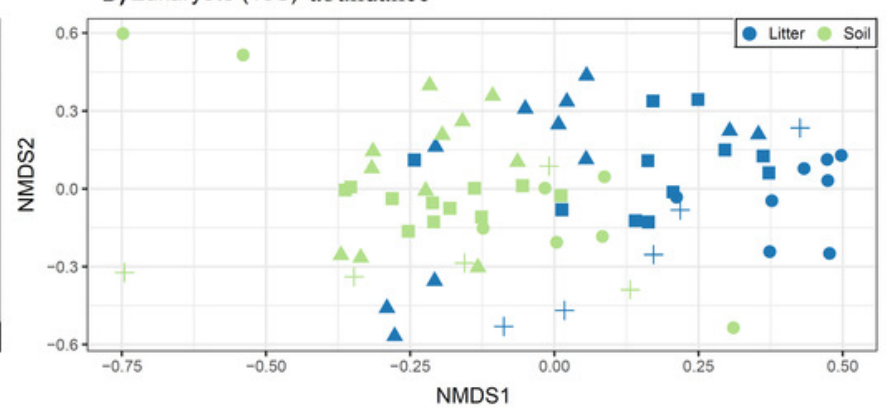


Figure 6

Taxonomic composition of Amazonian soil and litter micro-organismic communities.

The plots show the fraction of OTUs divided by taxonomic group for A) relative frequency of OTU presence for prokaryotes; B) relative abundance of OTU for prokaryotes; C) relative frequency of OTU presence for eukaryotes; D) relative abundance of OTU for eukaryotes. There is no clear taxonomic variation among groups in litter vs soil, in either the prokaryote or the eukaryote data for presence/absence. The relative abundance data shows a higher frequency of Actinobacteria in litter compared with soil and a higher abundance of Chloroflexi and Bacterioides in soil sample for prokaryotes. For eukaryotes is possible observe a highest relative abundance of Arthropoda and Chloroplastida in soil than litter samples.
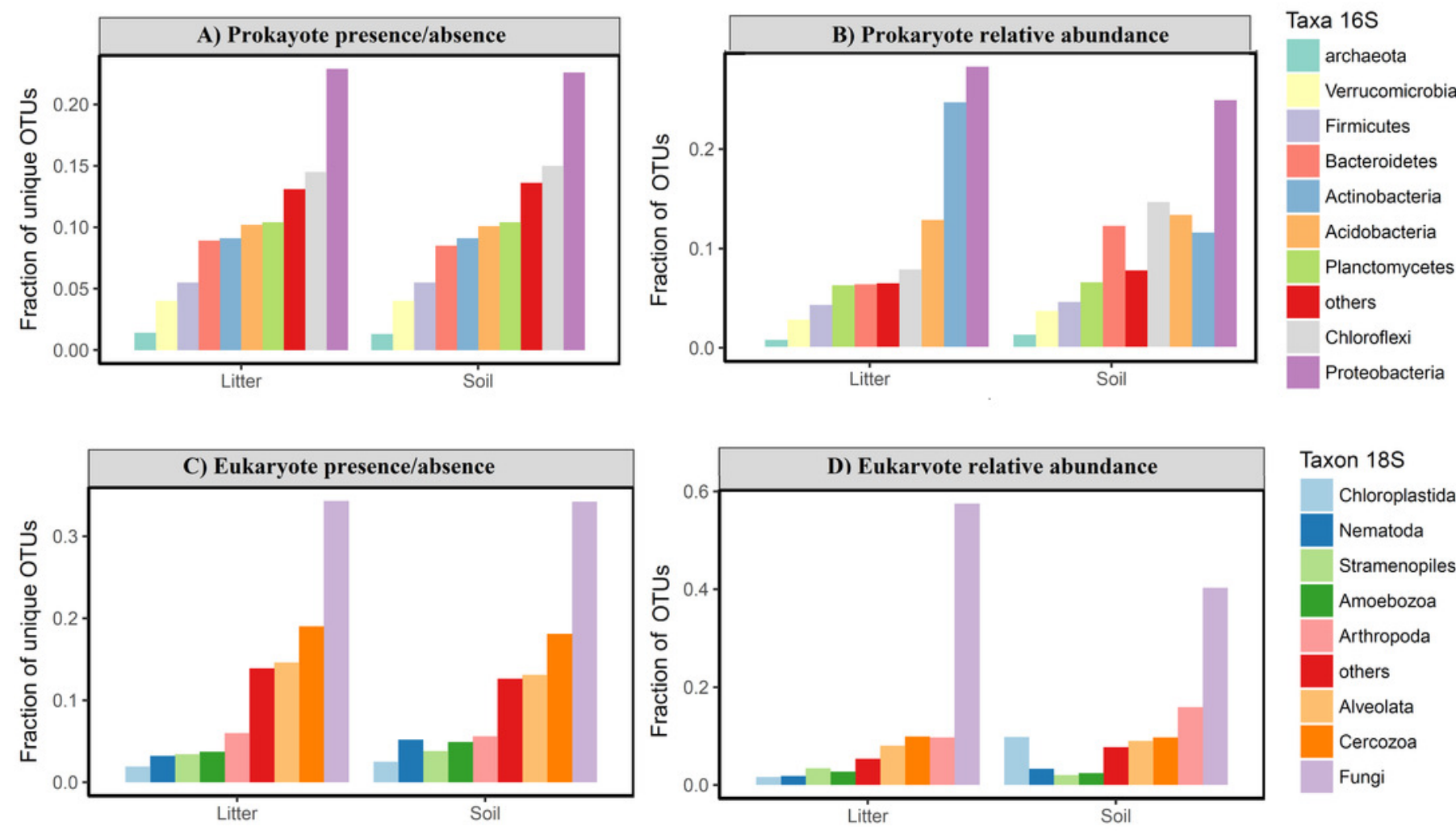

Taxon 18S

Chloroplastida

Nematoda

Stramenopiles

Amoebozoa

Arthropoda

others

Alveolata

Cercozoa

Fungi 